\title{
LA FUNDACIÓN DEL PARTIDO LIBERACIÓN NACIONAL Y EL ORIGEN DEL PROYECTO POLÍTICO EDUCATIVO SOCIALDEMÓCRATA EN COSTA RICA -Una aproximación hermenéutica crítica-
}

\author{
FOUNDATION OF NATIONAL LIBERATION PARTY AND THE ORIGIN \\ OF SOCIAL-DEMOCRATIC POLITICAL PROYECT FOR EDUCATION IN \\ COSTA RICA -A critical hermeneutic approach-
}

\section{Guillermo Miranda Camacho*}

\author{
RESUMEN
}

El objetivo central de este artículo es realizar una aproximación hermenéutica crítica, mediante el análisis de su discurso político, al proceso de configuración del proyecto político educativo del Partido Liberación Nacional (PLN), en su periodo fundacional, a principios de la década de 1950. Desde la perspectiva de análisis del discurso - bajo el enfoque hermenéutico crítico - se toma objeto de estudio la Carta Fundamental del PLN de 1951. Se analiza su contenido en referencia contextual con la coyuntura histórica en que se origina, los fundamentos ideológicos políticos del PLN y su proyecto político de orientación socialdemócrata.

PALABRAS CLAVE: COSTA RICA * PARTIDO LIBERACIÓN NACIONAL * PROYECTO POLITICO SOCIAL DEMÓCRATA * POLÍTICA EDUCATIVA * CAPITALISMO REGULADO * ESTADO DE BIENESTAR * ESTRUCTURA SOCIAL * DESARROLLO ECONÓMICO Y SOCIAL

\section{ABSTRACT}

This article approaches the process of development of the political project for education of Liberacion Nacional Party (PLN in Spanish) at the time of the latter's foundation during the decade of the 1950's. The approach is carried out from the perspective of critical hermeneutics through the analysis of the party's political discourse, taking as object of study the party's Fundamental Charter of 1951. Its contents are analyzed 
in contextual reference with the historical circumstances in which it originates, in the foundations of PLN's political ideology and its social-democratic political project.

KEY WORDS: COSTA RICA * PARTIDO LIBERACION NACIONAL * SOCIAL-DEMOCRATIC POLITICAL PROJECT * EDUCATIONAL POLICY * REGULATED CAPITALISM * WELFARE STATE $*$ SOCIAL STRUCTURE * ECONOMIC AND SOCIAL DEVELOPMENT

1. ANTECEDENTES DE LA FUNDACIÓN DEL PARTIDO LIBERACIÓN NACIONAL ${ }^{1}$

\subsection{EL CENTRO DE ESTUDIOS DE LOS PROBLEMAS NACIONALES}

El Centro de Estudio de los Problemas Nacionales (CEPN), establecido en marzo de 1940 , constituye una de las organizaciones fundamentales a partir de las cuales surgió el Partido Liberación Nacional (PLN). Sus antecedentes se remontan al año 1937 con la fundación de la Asociación Cultural de Estudiantes de Derecho que posteriormente fundó en 1939 el Consejo Estudiantil Universitario (después designado Federación de Estudiantes Universitarios de Costa Rica), organización que pasó de ser un grupo cultural a constituirse en un grupo político-universitario, que asumió una actitud crítica y propositiva frente a una coyuntura histórica convulsa y compleja de oposición al régimen oligárquico-liberal. Carlos Araya Pochet, indica que el CEPN corresponde a "la última etapa de integración de las juventudes intelectuales" (1969: 14). El CEPN emerge, en efecto, como un movimiento juvenil de intelectuales, en una década como la de 1940, caracterizada por una profunda conflictividad social y de luchas sociales e ideológicas frente al Régimen Oligárquico Liberal.

Desde su nacimiento a la vida política del país, manifestó su ideal de constituirse en un partido político auténticamente democrático.

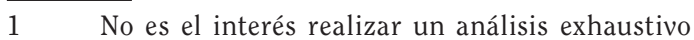
del origen y del proyecto político del PLN pues estos temas escapan a los objetivos de este artículo. Interesa, más bien, poner de relieve aquellos aspectos que se consideran fundamentales de su proyecto educativo según los propósitos de este artículo.
Su interpretación crítica de la realidad en esa coyuntura histórica va consolidando su orientación como grupo de interés político con clara visión de la problemática sociopolítica, económica y cultural costarricense. En efecto, como movimiento, irrumpe la escena política costarricense como una organización con plena conciencia histórica de la problemática nacional $y$ de su papel generacional ante los procesos de cambio; su ideario pasó a ser parte ideológica fundamental del proyecto político del Partido Liberación Nacional. Su génesis ideológica se fue configurando bajo el influjo del pensamiento de ilustres intelectuales costarricenses de la talla de Roberto Brenes Mesén, Carlos Monge Alfaro, Rodrigo Facio, entre otros no menos importantes. También nutrieron su ideario político la influencia del pensamiento de personalidades de proyección internacional, como Víctor Raúl Haya de la Torre (fundador del APRA en Perú y creador de teorías políticas acerca del cambio social en América Latina), la influencia de la Revolución Mexicana y la ideología política del socialismo reformista ${ }^{2}$.

Frente a estas corrientes oficiales comenzó a perfilarse - observa Alfonso Carro- una generación de jóvenes profesionales, estudiantes, empresarios y obreros, que preparó sus herramientas $y$ sus armas propias: el Centro para el

2 Para los efectos de este artículo utilizaremos indistintamente diversas denominaciones: socialismo reformista, social democracia, reformismo social. En algunos casos aparecerá el término socialismo que debe entenderse en el contexto marco doctrinal de ideología política del socialismo democrático. También se utilizan otros conceptos como: socialismo evolutivo, social revisionismo, gradua lismo o democracia social (Montenegro, 1986). 
Estudio de los Problemas Nacionales y el grupo político Acción Demócrata. De ella surgieron las ideas y las actitudes que reclamaban un cambio radical en la vida del país. Pronto entraron en conflicto con las esferas oficiales: compartían las tesis del avance social y la protección del trabajo, pero rechazaban sus métodos de Gobierno y la corrupción política que amenazaban con destruir las instituciones democráticas de la nación (Carro, 1986:15).

Surgía así, una visión política crítica frente a la hegemonía liberal en la primera mitad del siglo xx y con visión de futuro, adecuada a las particularidades de la nacionalidad costarricense, desde su ideología política socialdemócrata. El Centro, así como se opuso al liberalismo de don Ricardo Jiménez y don Cleto González y a los cafetaleros, estará - señala Delgado - en contra del gobierno de Calderón; lo acusan de hacer un régimen de corrupción y privilegios. Se opondrán al comunismo pero no a las fuerzas aliadas $y$ a la reforma social (1980:70). Las inquietudes intelectuales, los diagnósticos críticos, las propuestas de acción política fueron divulgadas en la Revista Surco, que en 1941, se constituye en el órgano oficial y el medio de divulgación del CEPN (Araya Pochet, 1969).

El estudio crítico de la compleja problemática del país, con la idea de tener una visión de conjunto de esa realidad, constituyó el objetivo central de este movimiento social de intelectuales (Delgado, 1980:29). Según Alfonso Carro (1986), José Figueres, Rodrigo Facio ${ }^{3}$ y Carlos Monge, "son hombres de ideas, no de ideologías; aunque como todos los hombres de ideas políticas importantes, han contribuido al desarrollo en Costa Rica del movimiento político de mayor influencia en los últimos treinta años: la Social Democracia" (1986:17). Como movimiento de orientación

3 Rovira (1983:42) destaca el valor de la obra "Estudio sobre economía costarricense", de Rodrigo Facio como la "presentación más acabada de diagnóstico que de la Costa Rica de entonces hacia el Centro partiendo de un enfoque histórico". política, el CEPN se estructura en comisiones especializadas dedicadas a la investigación de la problemática nacional $y$ a aspectos doctrinarios, cuyos dictámenes eran sometidos a discusión pública en asambleas ordinarias. Dichas comisiones, coordinadas por el Lic. Rodrigo Facio abarcaban diversos aspectos: agricultura, industria y fomento; asuntos sociales y económicos; hacienda, banca y comercio; educación, gobierno interior y legislación; relaciones exteriores $y$ salud. Muchas y muy diversas fueron las acciones de esta organización que realizó en aras de la crítica al liberalismo imperante que mostraba su incapacidad de responder a la problemática económica, social y política. Particularmente, ocupaba en esa década la decidida oposición de la clase dirigente oligárquica a las conquistas sociales logradas por el Presidente Dr. Rafael Ángel Calderón Guardia en su gobierno, con el apoyo decidido del Partido Vanguardia Popular y la Iglesia Católica ${ }^{4}$. La política durante el gobierno de Calderón Guardia estuvo centrada en lo social. La aprobación de las Garantías Sociales, la Caja Costarricense de Seguro Social y el Código de Trabajo, junto con la creación de la Universidad de Costa Rica, son las obras de mayor trascendencia de la primera mitad del siglo Xx (Salazar, 1985:67).

Al respecto, hay que considerar que las reformas sociales emprendidas en el gobierno del Presidente Calderón Guardia (1940-1944) consolidaron el Estado Social de Derecho en Costa Rica, que el CEPN veía incompleto y amenazado por la burguesía oligárquica. Según su visión política, una tarea política perentoria era allanar el camino para la instauración de un proyecto político reformista social. Asimismo, el CEPN adoptó una posición anticomunista

$4 \quad$ Hay que considerar al respecto que las bases más firmes, fruto de las reformas sociales emprendidas en el periodo del Presidente Calderón Guardia y desde luego, de su alianza con la Iglesia Católica y el Partido Vanguardia Popular consolidaron el Estado Social de Derecho en Costa Rica, allanando el camino para la instauración del Estado del Bienestar con el ascenso de los grupos sociales emergentes en 1948. Por lo demás, hay que reconocer otros antecedentes importantes, empero que su análisis escapa a los propósitos de este escrito. 
pues consideraba esta ideología política extraña a la realidad costarricense. Si bien, el núcleo ideológico fundamental del Centro era la socialdemocracia, lo cierto es también que no abandonó una fuerte dosis del liberalismo-democrático (Araya Pochet, 1969). Esto se explica quizás en parte por la heterogeneidad en la composición del CEPN, integrado por una amplia representación de la intelligentsia crítica y contestataria de la coyuntura histórica de los cuarenta, de diversas orientaciones ideológico-políticas. Muchos eran intelectuales de claro perfil humanístico, pero no de filiación ideológica socialdemócrata.

\subsection{VISIÓN EDUCATIVA DEL CENTRO DE ESTUDIOS DE LOS PROBLEMAS NACIONALES}

Una importante composición de la membrecía del CEPN estaba integrada por destacados educadores y jóvenes intelectuales ${ }^{5}$, por 10 cual era lógico que el análisis de la problemática educativa del país ocupara un lugar prioritario. Carlos Monge Alfaro e Isaac Felipe Azofeifa, intelectuales y educadores fundadores del Centro, habían realizado estudios universitarios en Chile y proponían ideas renovadoras en materia educativa, particularmente del movimiento pedagógico renovador chileno que acusaba influencia de la Escuela Nueva. Sus nuevas ideas pedagógicas no fueron comprendidas $y$ aceptadas por los grupos conservadores en el medio educativo selectivo y clasista del Régimen Oligárquico Liberal. En la Revista Surco, medio de comunicación oficial del CEPN, se publicaron numerosos artículos que preconizaban el cambio educativo.

Respecto a los principales postulados educativos del CEPN, el historiador Francisco Aguilar Bulgarelli (1983:91), observa que el más significativo está referido a la educación con fines democráticos, que se expresa en el tema "Educación para la democracia", título de un artículo de Isaac Felipe Azofeifa publicado

5 Entre ellos Carlos Monge Alfaro, Isaac Felipe Azofeifa Bolaños, Uladislao Gámez Solano, Roberto Brenes Mesén. También brindaron importantes aportes en la reflexión Jorge Rossi, Alberto Cañas, Fernando Jones entre otros (Aguilar, 1983:91). en la Revista Surco en $1940^{6}$. Aguilar señala que la idea central gravita en extender la educación a todas las capas sociales y que no fuera exclusiva de la clase económicamente dominante, esto es, de la oligarquía cafetalera. Según ese postulado, la educación debía llevarse a todos los rincones del país ofreciendo una educación "lo más completa posible"7.

Por otra parte, la Comisión de Educación del Centro concebía que la educación democratizada fuera al mismo tiempo universal y adaptada a las necesidades y posibilidades del país. Se planteaba, asimismo, la necesidad de la diversificación de la escuela urbana con la rural ante el hecho de que los programas de estudio eran iguales y no se tomaban en consideración las diferencias socioculturales de ambos medios ni las necesidades educativas particulares de la población rural de aquella época. Al respecto, la Comisión de Educación del CEPN proponía la realización de una reforma educativa en la enseñanza primaria "adaptándola a las necesidades del medio urbano y del medio rural" (Aguilar, 1983:93) ${ }^{8}$.

El exiguo desarrollo educativo de la educación media se ponía de relieve con la existencia en 1949 de apenas ocho colegios de secundaria en Costa Rica; fue hasta 1954, que el número de estudiantes alcanzó la suma de nueve mil estudiantes que se distribuían en veinticinco colegios. Esto explica porqué el foco principal de atención fue el de la reforma de la enseñanza media. Asimismo, en relación con la enseñanza media se proponía también la realización de una reforma a la formación humanística tradicional en aras de una formación de

$6 \quad$ Citado por Aguilar (1983:93): Azofeifa, Isaac Felipe. "Educación para la democracia". Revista Surco 8. Costa Rica: San Ramón. 1940: 4-5.

$7 \quad$ Es interesante hacer notar que la idea de una formación ciudadana - tan en boga en el desarrollo educativo mundial actual - ya era una preocupación de primer orden para el CEPN desde los inicios de la década de 1940.

8 Hasta la fecha no se ha cumplido del todo una política educativa que diferencie el medio rural del medio urbano. Esta sigue siendo una tarea pendiente del PLN $y$ una necesidad educativa fundamental para los sectores sociales que integran el medio rural costarricense. 
orientación científica que la complementara. Se proponía una educación que se adaptara a las necesidades de cambio de Costa Rica, introduciendo otros tipos de centros educativos especializados (escuelas de artes y oficios, granjas, etc.) y particularmente, se pretendía la introducción de la educación vocacional para dar oportunidad en el mercado laboral a miles de jóvenes que no podían asistir a los pocos liceos existentes en esa época. Respecto a la educación universitaria se planteaba la necesidad de que los futuros profesionales escogieran sus carreras, motivados por la función social de su realización y no simplemente animados por fines de lucro, como eran común en el ejercicio de profesiones liberales predominantes en el periodo de referencia. Complementariamente, a estos aspectos de cambio educativo, se analizaba la situación salarial de los educadores que constituía un desestímulo que conducía a la "pobreza intelectual" (Aguilar, 1983: 94-95).

Los puntos programáticos del CEPN en materia educativa fueron incorporados, como se verá en la Carta Fundamental del Partido Liberación Nacional en 1951 y posteriormente, fueron objeto de las políticas educativas de sus ulteriores gestiones gubernamentales.

\subsection{EL PARTIDO ACCIÓN DEMÓCRATA}

Otra organización opositora al Régimen Oligárquico Liberal fue el Partido Acción Demócrata (PAD) fundado en 1944, al cual pertenecía José Figueres Ferrer; fue este un organismo político que propugnaba por una mayor producción y equidad de su beneficio, en un marco de justicia y solidaridad social. El PAD tuvo como antecedente el grupo juvenil Acción Demócrata, que a su vez había surgido con el respaldo del Partido Demócrata de León Cortés. Aunque el PAD no poseía una producción de pensamiento político, ni de diagnósticos de la realidad nacional sistemáticamente elaborados, coincidía en los planteamientos básicos del CEPN, particularmente, en el papel interventor del Estado como un órgano que promovería un incremento en la producción, contribuiría en su organización y la equidad en la distribución de la riqueza. Según Rojas (1979:113), la diversificación de la producción y el desarrollo de las fuerzas productivas se constituyeron en objetivos del PAD orientados a la consolidación de una burguesía industrial. José Figueres Ferrer, líder de esta agrupación, también planteaba la perentoria necesidad de la diversificación de la estructura económica, frente al monocultivo del café y sus privilegios económicos y sociales junto a la tecnificación del agro. Desde el punto de vista social, consideraba que la justa distribución de la riqueza beneficiaría a los sectores más pobres y a los ricos, pues sostenía la tesis de la interdependencia del progreso social con el desarrollo económico. Es clara la adscripción del pensamiento del CEPN y de Figueres a las tesis económicas keynesianas y la doctrina política social demócrata, que emerge con inusitada fuerza en el periodo de posguerra en las que tuvo lugar el pacto keynesiano y la configuración del Estado del Bienestar.

Si bien el PAD no tenía una profusa producción de pensamiento político como el CEPN, lo cierto es que José Figueres Ferrer había consolidado, a través de la lectura y el estudio, una sólida visión política construida a partir de sus reflexiones críticas sobre statu quo de la vida nacional y su visión del futuro social, económico y político de la Costa Rica de mediados del siglo xx. En 1943, durante el periodo gubernamental de Rafael Ángel Calderón Guardia (1940-1944) y en el momento histórico en que la Segunda Guerra Mundial está en pleno apogeo, publica uno de sus principales escritos políticos: Palabras gastadas. Democracia, Socialismo, Libertad que, en nuestra opinión, constituye una de las piedras angulares doctrinales de la ideología socialdemócrata de la historia de nuestro pensamiento político y uno de los más emblemáticos documentos político-ideológicos del Siglo XX, en Costa Rica. Al desarrollar los conceptos o principios políticos enunciados en el subtítulo despliega el ideario político que desde su visión política, debe enmarcar el derrotero a seguir por la sociedad costarricense para construir un modelo de sociedad desde la visión de la socialdemocracia. En el contenido de ese ensayo 
político están las bases ideológicas del futuro Estado del Bienestar costarricense.

\subsection{EL ORIGEN DEL PARTIDO SOCIAL DEMÓCRATA: FUSIÓN DEL CENTRO DE ESTUDIOS DE LOS PROBLEMAS NACIONALES Y EL PARTIDO ACCIÓN DEMÓCRATA}

En 1945 tuvo lugar la fusión del PAD $y$ el CEPN que dio origen al Partido Social Demócrata (PSD) el cual asumió, ideológica y políticamente, la integración de las ideas socialdemócratas de ambas organizaciones y su visión crítica, junto con las propuestas de acción política ante la problemática social, económica, política y cultural que experimentaba Costa Rica. Su principal vértice ideológico y programático de lucha política se centro en la crítica al gobierno de Teodoro Picado por corrupción, la manipulación de las elecciones y su interés en mantenerse en el poder, la disminución de las libertades civiles en el periodo de la Segunda Guerra Mundial, la alianza del calderonismo ${ }^{9}$ con el Partido Vanguardia Popular (Partido Comunista) que veían como una amenaza y de manera particular, su posición a la burguesía oligárquica. El PSD respaldó la Guerra Civil que Figueres venía planeando desde 1942, con la obtención de armas, el establecimiento de las condiciones militares, en particular con la formulación de una estrategia para su realización. Ante la urgencia de participar en los comicios electorales de 1948, se alió con sectores conservadores ante la imposibilidad de José Figueres Ferrer de asumir la candidatura a la presidencia, con lo cual optaron por apoyar

$9 \quad$ Salazar (1985:205) señala que, el calderonismo tenía su base social de apoyo en los sectores urbanos, obreros y grupos marginados o subproletariado y en la clase obrera de las zonas bananeras. Asimismo, indica que el respaldo de estos sectores se debía a la legislación laboral de orientación socialcristiana que el Dr. Calderón Guardia había impulsado con el apoyo del Partido Vanguardia Popular (Partido Comunista) y de la Iglesia Católica en su periodo gubernamental de 1940-1944. a Otilio Ulate Blanco (periodista conservador crítico, Director del Diario de Costa Rica) quien resultó ganador, pero cuyas elecciones fueron otorgadas al partido oficial tradicionalmente de la Oligarquía Cafetalera: Partido Republicano Nacional (Jonas, 1984:18-19). En esta coyuntura histórica, fue este el motivo (o justificación) invocado por José Figueres Ferrer para desencadenar la Guerra Civil de 1948, asumiendo el mando del Ejército de Liberación Nacional, que llevó a los sectores sociales emergentes $^{10}$ de orientación socialdemócrata y críticos de la burguesía oligárquica a tomar el poder para llevar adelante su proyecto político.

Solís y Esquivel (1980) señalan que la Guerra Civil de 1948, que llevó adelante el Ejército de Liberación Nacional, tuvo como objetivo fundamental el impulso del proyecto político de orientación reformista pequeño burgués (según su conceptualización) consolidado en el periodo de 1942 a 1948. Siguiendo esta tesis, la consolidación de ese proyecto político era precisamente la que sostenían los sectores sociales aglutinados en el CEPN, el PAD $y$ posteriormente, el PSD $y$ otras fuerzas sociales y políticas, así como, grupos sociales que asumían una posición crítica frente al Régimen Oligárquico Liberal. Por otra parte, sostienen que el reformismo pequeño burgués devino en un reformismo burgués, cuyo principal propulsor sería el Partido Liberación Nacional (PLN).

$10 \quad$ Entre los sectores sociales emergentes estaban los jóvenes intelectuales que habían pertenecido al CEPN, los líderes intelectuales y políticos del Partido Social Demócrata, grupos de técnicos y empresarios pertenecientes a los sectores medios. El Estado del Bienestar, el desarrollo de una clase media, la modernización de la estructura capitalista mediante la instauración de una estructura social de acumulación de capitalismo regulado, la modernización de la estructura productiva, la modificación de las reglas del juego democrático en la escena política, la ejecución de fuertes políticas sociales, entre otras medidas y objetivos, constituían las bases del proyecto político social demócrata que preconizaban los sectores emergentes. 


\section{LA FUNDACIÓN DEL PARTIDO LIBERACIÓN NACIONAL: PRINCIPALES ORIENTACIONES DE SU PROYECTO POLÍTICO}

Como se ha señalado, el surgimiento del PLN tiene lugar en un periodo que se inicia al finalizar la Segunda Guerra Mundial, en el cual el sistema capitalista mundial es reorganizado con base en un amplio consenso social en torno al crecimiento y la redistribución entre las diversas clases y grupos sociales. Cada Estado Nacional, que se adscribe a este proceso de negociación política, regula las condiciones para emprender ese crecimiento y la redistribución. Particularmente, la forma de concreción de esa reorganización es el resultante de una negociación entre capital y trabajo. El significado histórico de la fundación del PLN debe interpretarse, por consiguiente, en el marco de este proceso histórico en que tiene lugar el llamado Pacto Keynesiano y el proceso de configuración del Estado del Bienestar. Una aproximación hermenéutica crítica a la Carta Fundamental del PLN, como documento político-ideológico, por consiguiente, debe analizarse teniendo en consideración estos elementos de contexto.

\subsection{ADVENIMIENTO DEL CAPITALISMO REGULADO EN COSTA RICA Y DEL ESTADO DEL BIENESTAR}

Uno de los hechos más significativos, desde el punto de vista político económico, que caracteriza el periodo de referencia, es el surgimiento de una nueva estructura social de acumulación: el momento histórico del origen del capitalismo regulado, que iniciará su fase de consolidación y expansión del año 1946 hasta inicios de la década de 1970, en un ciclo económico conocido como del "largo boom", en alusión al auge económico del ciclo de acumulación de capital en su etapa expansiva. Como observa Riutort (2001), este proceso requería de un entorno social que estableciera las condiciones estructurales de su concreción, esto es, de la instauración y articulación de una estructura social de acumulación, que se constituyera en un factor impulsor $y$ dinamizador que incidiera en el aumento o disminución de la tasa de beneficio.

El entorno social está constituido comenta Riutort (2001: 18)- por un conjunto articulado de hábitos, costumbres, convenciones, administraciones, contratos, derechos de propiedad, legislaciones, etc., que para cada sociedad y época histórica, facilitan $y$ estimulan el mantenimiento de una tasa de beneficio suficiente, por tanto, la inversión de capital.

En esta línea de pensamiento, la estructura social de acumulación se constituye en un conjunto articulado de condiciones sociales, políticas, jurídicas, ideológicas e institucionales que asume y promueve el Estado capitalista para fomentar, a través de sus políticas públicas, las condiciones de logro políticas, jurídicas e institucionales que posibiliten el proceso de acumulación ampliada de capital en la fase expansiva de un ciclo económico. El establecimiento de la estructura social de acumulación del capitalismo regulado - como se puso de manifiesto ostensiblemente en el caso de Costa Rica- se complementó con la aportación de valores de uso de la fuerza laboral, mediante políticas sociales como expresión del papel intervencionista que asumió el Estado del Bienestar. La estructura social de acumulación del capitalismo regulado que se empezó a configurar en la década de los cincuenta, pretendía desplazar el eje de la acumulación de capital del Régimen Oligárquico Liberal, basada fundamentalmente en la producción y exportación cafetalera, hacia una nueva estructura social de acumulación de capitalismo regulado, que propiciara la modernización de la estructura económica capitalista mediante una decidida intervención estatal en la dinámica del sistema económico.

Los principales aspectos programáticos que proponía el CEPN y que fueron asumidos por el Partido Social Demócrata y posteriormente, por el proyecto político del PLN se constituían en los ejes alrededor de los cuales 
se articularía la estructura social de acumulación de capitalismo regulado en Costa Rica. Esta orientación de política económica, como estrategia de legitimación del capitalismo regulado dependiente, ya había sido propuesta por Rodrigo Facio y acogida en los círculos del CEPN. Asimismo, había sido retomada en el proyecto político del Partido Social Demócrata $y$ luego en el del PLN. Entre los principales ejes estaban: a) la diversificación de la producción tendente a modernizar la estructura capitalista y por ende, a ampliar la participación en la actividad económica de los nuevos sectores sociales emergentes vinculados a la actividad económica; b) el cooperativismo como unidad básica de la nueva organización productiva; c) el Estado como organizador de todo el proceso; d) la propuesta de un modelo de desarrollo cuyo principal vértice era la industrialización (para superar el estado de estancamiento en esta rama económica, que apenas mostraba un "despegue incipiente") (Rovira, 1983: 43).

Así pues, en Costa Rica se siguió el mismo patrón de instauración del capitalismo regulado estableciendo una acomodación keynesiana, pero en el marco de las posibilidades de cambio estructural que admitían las particularidades de la formación social costarricense de capitalismo dependiente. En el proceso de configuración de la acomodación keynesiana en Costa Rica, los derechos de propiedad $y$ los derechos sociales $y$ políticos se conciliaron, mediante un modelo de Estado con una estructura social de acumulación, que propiciaba un proceso de modernización de la estructura capitalista, alternativo al anquilosado sistema económico cuya dinámica dependía básicamente de la producción cafetalera y con la instauración de una fuerte institucionalidad que promoviera la superación de las marcadas desigualdades sociales. La estrategia, por lo tanto, consistía en promover la diversificación agropecuaria e industrial en aras de un proceso de acumulación de capital y de expansión de la tasa de ganancia, que si bien favorecía al capital (ahora con los nuevos sectores empresariales emergentes), establecía concomitantemente un equilibrio, una suerte de concertación social, que posibilitaba una nueva relación capital/trabajo.
Una vez iniciado el gobierno de Otilio Ulate Blanco ${ }^{11}$ (1949-1953) y ante el fracaso en la Asamblea Nacional Constituyente ${ }^{12}$ de aprobar el Proyecto de Constitución Política presentada por la Junta de Gobierno — de acentuado carácter social reformista- los sectores sociales emergentes se aprestaron a fundar en 1951, su propia agrupación política, el PLN, que irrumpirá en la escena política costarricense para retomar el camino del Estado del Bienestar, el desarrollo de la estructura social de acumulación del capitalismo regulado, las políticas sociales benefactoras $y$ el impulso de la modernización reformista en el marco de un capitalismo regulado.

\subsection{FUNDACIÓN DEL PARTIDO LIBERACIÓN NACIONAL: PRINCIPALES FUNDAMENTOS IDEOLÓGICOS-POLÍTICOS}

El impulso del proyecto políticoeconómico reformista, como expresión de los intereses de los sectores sociales emergentes de orientación socialdemócrata, requería establecer una presencia activa $y$ permanente en la escena política costarricense con una agrupación político-partidista. La fundación del PLN, tuvo lugar el 12 de octubre de 1951, en San Ramón, Alajuela, con la firma de la Carta Fundamental, su primera fuente doctrinaria. Con la fundación del PLN, los sectores sociales emergentes ya contaban a principios de la década de 1950 con un instrumento de lucha política para posicionarse en la escena política costarricense. El liderazgo de José

11 En virtud del denominado "Pacto Figueres-Ulate", José Figueres se comprometía a entregar el poder a Otilio Ulate, una vez consolidado el triunfo del Ejército de Liberación Nacional. Ulate asumió la presidencia concluido el gobierno de facto de dieciocho meses de la Junta de Gobierno de la Segunda República, que presidió Figueres.

12 El Partido Social Demócrata apoyó el Ejército de Liberación Nacional en la Guerra Civil de 1948 y el "gobierno de los dieciocho meses" de 1948 a 1949. En la elección de los diputados de la Asamblea Nacional Constituyente de 1949, solo obtuvo cuatro diputados: Rodrigo Facio Brenes, Fernando Fournier Acuña, Luis Alberto Monge Álvarez y Rodrigo Valverde Vega. 
Figures Ferrer lograba aglutinar políticamente a un grupo de jóvenes intelectuales, técnicos y empresarios de "clase media" (Vega, 1982).

\section{CONCEPCIÓN ANTROPOLÓGICA-POLÍTICA} DEL SER HUMANO

El norte ideológico de la Carta Fundamental del PLN define en su primer artículo la concepción del ser humano. La visión antropológica-política de la persona humana será una conjunción de un ser individual, social, espiritual y material que se constituye en fin $y$ no en medio, con un destino personal intransferible, con determinación propia, inspirado en valores que solo él es capaz de intuir, dotado de dignidad y derechos inalienables, el norte ideológico que inspirará el corpus doctrinal de la Carta Fundamental del PLN (Art. 1: 1951). La definición que se asume se respalda doctrinalmente con la Declaración Universal de los Derechos del Hombre ${ }^{13}$.

Los derechos del hombre, por ser éste digno y libre, son inherentes a su propia naturaleza y ningún poder, ningún conjunto de fuerzas, puede justificar su violación. Los derechos del hombre son el instrumento indispensable para la realización de su propio destino y para coadyuvar a cumplir el destino de la comunidad (Art. 2: 1951).

\section{CONCEPCIÓN DEL ESTADO}

El proceso histórico social en Costa Rica, que tuvo lugar el asenso de los sectores sociales emergentes y la consolidación del proyecto político socialdemócrata discurre en un momento, como lo hemos indicado, en que el modelo teórico de Keynes, como formulación teórico-económica, se constituye en la base

13 La Asamblea General de las Naciones Unidas aprobó el 10 de diciembre de 1948, en París, la Declaración Universal de Derechos Humanos (Resolución 217 A (III)). Tres años después, el PLN recogía en su Carta Fundamental este cuerpo jurídico internacional. científica sobre la cual se edifica en el mundo occidental, el Estado del Bienestar. En efecto, la etapa inmediatamente posterior a la finalización de la Segunda Guerra Mundial, tiene lugar el proceso en el cual los países industriales occidentales con mayor desarrollo capitalista asumen el denominado pacto keynesiano, que se convierte en un modelo de regulación social y económica basado en un acuerdo tácito entre el capital y el trabajo, con la concomitante irrupción del Estado del Bienestar. Con este modelo se pretendía la liquidación de la política del laissez faire $y$ al nacimiento de una nueva política económica basada esencialmente en la intervención sistemática del Estado. Por consiguiente, el Estado asume un papel económico central ejerciendo una función directiva sobre la propensión al consumo, a través de la política fiscal, la socialización de las inversiones y la política del pleno empleo. Si bien, en el sistema teórico propuesto por Keynes la iniciativa privada continúa teniendo un papel decisivo, ya no es considerada el único motor del progreso, puesto que el equilibrio general del sistema puede ser garantizado solo por una política orgánica de intervenciones estatales dirigidas a enfrentar las crisis cíclicas.

Históricamente, el Estado del Bienestar se articuló en torno al pacto keynesiano, asumiendo una función de arbitraje institucionalizado frente al conflicto industrial histórico y al mismo tiempo, interviniendo con sus políticas públicas para solucionar los "fallos del mercado" a partir del reconocimiento de que el mercado es incapaz de solucionar las contradicciones entre el carácter social de la producción y la propiedad privada de los medios de producción. En el plano económico, su carácter intervencionista se define por la tesis de que el sistema económico no podría abandonarse a los influjos mediáticos y casuísticos de la libre oferta y la demanda, de las condiciones sociales de la reproducción de la fuerza de trabajo. El carácter intervencionista del Estado del Bienestar y su marco regulador emergen como fuerzas políticas supremas para establecer la paz social entre capital $y$ trabajo.

Como lo hemos puesto de relieve en otro momento (Miranda, 2007a), Claus Offe 
lo concibe como la fórmula pacificadora de las democracias capitalistas avanzadas para el periodo de posguerra. Su fórmula de paz ha consistido en la obligación explícita del aparato de estado de suministrar asistencia y apoyo a la ciudadanía que sufren necesidades o riesgo específicos característicos de la sociedad mercantil. Su estrategia de legitimación se basa, en consecuencia, en una suerte de pacto social y el reconocimiento del papel formal de los sindicatos en la negociación colectiva $^{14}$ y en la formación de los planes públicos. Dimensiones que fueron expresión del pacto entre capital $y$ trabajo para mitigar las contradicciones inherentes a las relaciones sociales que históricamente han contraído en el capitalismo liberal (Offe, 1990:135-136).

Desde su origen, el PLN orientó su acción política ideológica desde una concepción de Estado de carácter intervencionista. Su proyecto político fue concebido siguiendo las orientaciones doctrinales políticas, sociales $y$ económicas mencionadas anteriormente, pero atendiendo a las particularidades históricas estructurales de la formación social costarricense. El modelo de Estado del Bienestar costarricense en el artículo 6 (1951) de su carta constitutiva se definió así:

El Estado es la organización político jurídica del poder de la sociedad, encargada de garantizar los derechos de los individuos, debe realizar por medio del orden jurídico, todas aquellas funciones en las cuales su intervención se justifique por motivos del bien común, que en ningún caso, puede justificar el sacrificio de los atributos fundamentales de la dignidad humana (la cursiva es propio).

De acuerdo con las consideraciones precedentes, la concepción del Estado que preconiza el PLN en su Carta Fundamental de 1951, está cimentado en dos frentes: por una

14 Por consiguiente, la negociación colectiva de trabajo se constituye en un instrumento jurídico laboral básico de las organizaciones sindicales, como expresión del nuevo pacto social —entre capital y trabajo- que representa el Estado del Bienestar. parte, se convierte en Estado intervencionista, que participa activamente en la economía para generar empleo público (construcción de infraestructuras públicas como escuelas, hospitales, carreteras, etc.). Y por otra, asume un modelo de Estado que —siguiendo lo que indica Castells (1996) - crea y consolida una importante red de cobertura social, en terrenos como la vejez, la enfermedad, el desempleo, los servicios sociales, etc. Esta orientación se concretó, en el objetivo 9, estableciendo el deber estatal de "ayudar a los grupos económicos débiles". En esta misma perspectiva se admite, como parte del pacto socialdemócrata de posguerra, la capacidad de lucha de los trabajadores "a través de sus organizaciones constituidas democráticamente".

En el artículo 3, se plantea la integración de productores privados con el establecimiento de organismos económicos-sociales, que "los regulan, ayudan y fomentan”. El aparato de Estado, pensado en una economía de abundancia, tiene como propósito la satisfacción de las necesidades de la colectividad, por lo tanto, requiere de un sistema de instituciones económicas, que racionalicen $y$ hagan eficiente $y$ efectiva la política económica para la instauración de la estructura social de acumulación del capitalismo regulado en Costa Rica ${ }^{15}$. En esta dirección el PLN propone el establecimiento de un sistema institucional que combine la empresa particular con el organismo estatal autónomo, que responda a una vocación de servicio en aras del interés público.

\section{LIBERTAD Y PROPIEDAD PRIVADA}

A diferencia del principio político de libertad, que desde la concepción del liberalismo, acentúa su significado en la libertad individual concebida como un derecho inviolable y cuyo único límite consiste en la libertad de los demás; en la Carta Fundamental se asume

15 Las medidas adoptadas por la Junta de Gobierno en el "gobierno de los dieciocho meses", así como, el desarrollo de un amplio y diverso régimen de instituciones autónomas obedeció a la configuración de la estructura social de acumulación del capitalismo regulado en Costa Rica. 
un carácter distinto respecto de este principio político-ideológico cardinal:

Concebimos la libertad como ámbito natural para la realización plena de la persona humana. Por lo tanto, la entendemos como un concepto integral que incluye no solo el disfrute de los tradicionales derechos civiles y políticos sino también la máxima satisfacción posible de las necesidades de alimentación, vivienda, vestido, salud, y educación (Art. 3: 1951).

La libertad, como se desprende de este artículo, trasciende el carácter individual para adquirir un rango de naturaleza integral y colectiva que tiene como centro gravitacional el bien común. La dimensión integral del principio político de libertad radica en su vinculación temática con el corpus doctrinal del socialismo reformista que prioriza la política social, en concordancia con el Estado del Bienestar, que impulsaban los sectores sociales emergentes aglutinados en el nuevo partido socialdemócrata.

Entre las tesis socialdemócratas a las que se adhiere el nuevo partido político aparece con meridiana claridad, su posición respecto de la propiedad privada. En el artículo 9 de la Carta Fundamental del PLN de 1951 se estableció doctrinalmente su función social, su carácter de hecho social generalizado, su utilidad pública y su organización racional en aras del Bienestar social.

\section{DEMOCRACIA}

Eduard Berstein había establecido una íntima vinculación entre el socialismo reformista y la democracia; al respecto había indicado que: "La democracia es, al mismo tiempo, un medio y un fin. Es un medio de lucha para el socialismo y es la forma que el socialismo adoptará una vez que haya sido realizada" (citado en Montenegro, 1986: 217). Desde esta concepción concibió, como principio socialista, la vinculación programática de la democracia como medio de lucha. En concordancia con este principio, en el contexto discursivo político de la Carta Fundamental del PLN, los métodos políticos de participación popular, sufragio popular y el ejercicio democrático de la ciudadanía, de las libertades públicas y de los derechos civiles devienen en medios de lucha para asumir críticamente el ejercicio del poder. En consecuencia, el proyecto político reformista social del PLN establece que "el sistema democrático de gobierno debe ser fortalecido y perfeccionado; ha de descansar efectivamente en el sufragio libre, consciente y universal".

Al referirse a la constitución de la Segunda República en la década de 1940, José Figueres Ferrer definió la democracia en los siguientes términos:

Democracia es una sociedad en que cada individuo tiene conciencia clara de lo que el grupo hace; es la colaboración de todos en el manejo de lo que a todos pertenece; colaboración que se manifiesta en forma ordenada y racional, ya sea emitiendo un voto para elegir un funcionamiento, o contribuyendo públicamente a la solución de una dificultad, o censurando procedimientos nocivos, o simplemente aprobando con el silencio las actuaciones de quienes ejecutan la voluntad general (Figueres, 1986: 97).

Es interesante observar la plena coincidencia de la concepción de democracia de Figueres con el planteamiento doctrinal de Berstein, en el carácter que le confiere como medio de lucha a través de los medios que la misma democracia posee. A este respecto, Carlos Monge Alfaro señala que el grupo que rodeaba a Figueres aspiraba, desde el punto de vista programático, no solo a rescatar y mejorar las instituciones electorales sino a conferirle a la democracia un eficaz contenido social. "A la libertad política - expresa Monge- se le agregaron otras, la justicia social y la justicia económica" (1984). Asimismo, en la definición de Figueres se pone de relieve su actitud crítica frente al Régimen Oligárquico Liberal que le llevarían a desencadenar la Guerra Civil de 
1948 y al proceso de instauración del Estado del Bienestar costarricense.

En la Carta Fundamental del PLN existe una clara concordancia conceptual con los principios doctrinales mencionados, al poner en primer plano la vía democrática como medio para alcanzar el Bienestar común aspiración suprema de la vida social-y que se concreta en el sistema político. Pero más aún, el discurso político doctrinal del PLN en su Carta Fundamental es coincidente con el papel que se le confirió a la socialdemocracia, en aras de la reconstrucción de las naciones afectadas por la Segunda Guerra Mundial, privilegiando los problemas del desarrollo en la dirección de diseñar y la puesta en práctica de reformas sociales, económicas y políticas. Desde esta visión, se define un papel del Estado que si bien impulsa un conjunto de políticas públicas tendentes a solucionar la problemática social, al mismo tiempo, respeta las libertades individuales, la primacía de un Estado de derecho, el orden constitucional, el pluralismo político y la armonía entre la sociedad política y la sociedad civil.

Es precisamente en esta cuestión, en donde se establece la concepción del sistema político correspondiente al Estado del Bienestar $y$ en consecuencia, un régimen de orientación socialdemócrata. Esta síntesis integrativa pone en primer plano el bien común compartido entre el capital y el trabajo, que ahora superaran, mediante un pacto social, su antagonismo de clase en aras del bienestar colectivo impulsado y regulado por el Estado del Bienestar y todo su aparato. La democracia se definió en la Carta Fundamental así:

La democracia es un sistema político inspirado en el respeto a la dignidad humana, dentro de ella el gobierno es una delegación consciente de las facultades soberanas del pueblo y se ejerce con respeto a las minorías, la consideramos como el mejor medio para la realización plena de nuestros ideales por bienestar general (Art. 7: 1951).

En la búsqueda de una base social de apoyo a su proyecto político el PLN encauzó la estrategia de legitimación de ese proyecto en los sectores sociales intermedios de la estructura social. Al respecto, Delgado destaca que su orientación mesoclasista se basó en la desviación de las atenciones de las mayorías a las capas sociales intermedias, entre los que destaca los intelectuales y los empleados, incluyendo algunos sectores de la pequeña burguesía urbana y rural (campesinos, comerciantes, industriales, artesanos) que se colocaron en el centro del nuevo orden político y la conciliación (Delgado, 1980: 94-95). Es claro, entonces que la asunción del pacto social de posguerra fue asumida por los nuevos sectores sociales emergentes aglutinados en el PLN. Precisamente en esta tesitura, como se intentará demostrar, se asume la educación como una preocupación central del proyecto político social demócrata del PLN.

\section{BIEN COMÚN}

Es en torno al concepto de bien común, en donde la educación ocupa un lugar central en el espacio ideológico social-demócrata y en el cual converge todo el discurso ideológico del PLN. El concepto de bien común ha sido definido así en su Carta Fundamental:

Por el bien común entendemos condiciones de vida que garanticen el desarrollo integral del hombre en el ejercicio de sus derechos; $y$ una distribución del producto de la actividad económica, que proporcione a todos y a cada uno, las normas de vida más elevadas que permita la productividad del grupo social (Art. 5:1951).

La sociedad concebida para que el ser humano alcance sus propios fines, implica que la vida social es el cumplimiento de los deberes $y$ derechos de los ciudadanos para la realización del bien común (Art. 4: 1951). En consecuencia, la estructura social de acumulación del capitalismo regulado, igualmente se debe articular en torno al principio socialdemócrata del bien común, en particular la vertebración del ordenamiento jurídico a partir de la Constitución de 1949 y en un 
sistema institucional adaptado a la realidad nacional. En esto queda la clara evidencia de la intención de adaptar la ideología social demócrata a las particulares características sociohistóricas del país.

La institucionalidad del Estado del Bienestar y sus políticas públicas tendrán así, su orientación y articulación en torno al principio del bien común (objetivo 8). En la búsqueda de sanear la administración pública y someterla a un sistema coordinado y regulado por el Servicio Civil, el Estado subordina la ejecución de todas las acciones tendentes al logro de estos objetivos, a la realización del bien común y al ordenamiento jurídico público.

\section{PLANEAMIENTO ECONÓMICO}

Entre los aspectos más importantes que interesan destacar del primer objetivo está, en primer término, la concepción de que la solución a los "vicios heredados el antiguo régimen liberal" se encuentra en el planeamiento económico (objetivo 1). Esa referencia a los vicios está directamente vinculada con la dinámica económica capitalista liberal, que sin mecanismos de regulación provocan una creciente polarización social a través de una concentración de la riqueza económica en un reducido grupo de capitalistas que controlaban la producción y exportación del café, el capital dinerario y el mercado, con la importación de bienes de consumo. Es interesante observar que una acción como la que se propuso, quedó supeditada a acciones que no violenten la dignidad humana y el logro de los fines del bien común.

El principio rector del papel de la planificación quedó así planteado en la Carta Fundamental:

El Estado debe formular planes nacionales de desarrollo. Por tanto, deben existir organismos planificadores y reguladores que el gobierno central coordine efectivamente con las instituciones autónomas, las comunidades, $y$ las actividades privadas (...) Creemos que, en cada etapa del desarrollo y para todo tipo de actividades en el proceso productivo, hay algunas funciones que el Estado efectúa mejor y otras que son llevadas a cabo más efectivamente por la empresa privada... (PLN, 1969: 8).

La planificación, las políticas económicas y el desarrollo se integran en el proyecto político del PLN en una acción que converge en superar las condiciones estructurales de la pobreza y simultáneamente, a crear las condiciones de modernización del sistema económico $^{16}$. Desde el punto de vista de la doctrina keynesiana, la planificación económica se constituye, por consiguiente, para el Estado del Bienestar como un factor estabilizador interno de tipo económico y político que ayuda a regenerar las fuerzas del crecimiento económico y evita la crisis descendente hacia profundas recesiones (Offe, 1990). Todo lo anterior en el marco de un capitalismo regulado, es decir, con una decidida intervención estatal que propende a una economía mixta, articulando por medio de acciones de políticas públicas, a los sectores público y privado. Ese papel recayó en gran medida en las instituciones autónomas. La implantación de un régimen de instituciones autónomas obedecía, por consiguiente, a asegurar ese papel estatal. El sector público - como observa Vega, 1982 - se transformó en motor principal que impulsó la modalidad de acumulación capitalista con fuertes inversiones sociales y redistribución de ingresos, en un esquema de interpenetración de la sociedad y el Estado.

El énfasis puesto en el planeamiento económico deber verse en un plano general, por lo tanto, como una acción destinada a la superación del capitalismo del Estado liberal oligopolio, para realizar gradualmente los pasos necesarios en aras de instaurar un capitalismo regulado basado en la acomodación keynesiana. Esto es, basado en un Estado de capitalismo regulado que, como se desprende del objetivo 2 , concilie e integre, mediante una estrategia

16 La institucionalización de la planificación por parte del Estado del Bienestar costarricense, se pudo concretar institucionalmente hasta en el gobierno de Francisco J. Orlich con la creación de la Oficina Nacional de Planificación en 1961. 
de carácter corporativista y con su intervención reguladora, la relación entre el capital y el trabajo a partir del reconocimiento del carácter social de la función económica. En la base de esta orientación está la conciliación y desarrollo de los derechos de propiedad y los derechos políticos y sociales típicos del Estado del Bienestar, mediante la intervención estatal y un marco jurídico e institucional. Debe ponerse de relieve, asimismo, el carácter gradual del cambio, en correspondencia doctrinal con el principio político de la evolución orgánica -que preconizaba Berstein- en la búsqueda de la justicia y la armonía social para mejorar las condiciones de vida de la masa de trabajadores y teniendo como meta final el Bienestar general de la colectividad. Asimismo, se asume el compromiso por la elevación de la cultura respetando la nacionalidad costarricense.

En la perspectiva de los cambios estructurales requeridos para impulsar el proceso de modernización capitalista en Costa Rica, los organismos internacionales desempeñaron un papel de capital importancia a través de sus propuestas programáticas. Un ejemplo de ello lo fue el modelo de la Comisión Económica para América Latina (CEPAL) de desarrollo hacia dentro, con la industrialización como motor del desarrollo económico y por ende, del proceso de acumulación de capital promovido por tecnocracia costarricense, cuyos funcionarios asumen labores en el aparato del Estado del Bienestar costarricense con la condición de intelectuales orgánicos (según el concepto gramsciano). Estos procesos requirieron de la introducción de la planificación sectorial promovidos por la CEPAL, con el acompañamiento de una fuerte intervención técnica, desde las acciones estatales, para asegurar la implantación de esos procesos. Lo mismo ha ocurrido en el proceso de cambio educativo que ha tenido lugar desde la década de los cincuenta, el cual ha requerido en forma creciente, del concurso de la tecnocracia especializada en ese campo para formular una política educativa expresada en las diversas propuestas de reformas educativas que se llevaron a cabo en el curso de las década de 1960 (reforma de la enseñanza media) y de principios de 1970 (Plan
Nacional de Desarrollo Educativo) de reformas con arreglo a los requerimientos de proceso de modernización del capitalismo regulado.

\section{EQUIDAD}

El principio socialdemócrata de la equidad se estableció como un objetivo fundamental para garantizar una relación armónica, una paz social de naturaleza estructural, garante del pacto entre capital y trabajo. El desarrollo del cooperativismo es visto como una acción fundamental tendente a la democratización económica, así como el fortalecimiento de un movimiento sindical acorde con su ideología, como parte de la relación capital/ trabajo. Este se concretó con la Confederación de Trabajadores Rerum Novarum, fundada por el Presb. Benjamín Núñez; esta organización no contó con un amplio apoyo del sector obrero (Aguilar, 1981). Por otra parte, del objetivo 3 y 8 destacan el establecimiento de "un sistema de instituciones económicas idóneas" y "adaptadas a la realidad nacional", poniendo de relieve el acentuado interés en implantar una estructura social de acumulación propia del capitalismo regulado. La nacionalización de la banca, la diversificación agrícola, el apoyo al modelo de desarrollo industrial (sustitutivo de importaciones), la nacionalización de la electrificación y la creación del Instituto Costarricense de Electricidad (ICE), el apoyo a los fundamentos legales e institucionales del Estado Social fruto de la reforma social de los años cuarenta-, el fortalecimiento del sistema electoral, la abolición del ejército, el fortalecimiento y expansión institucional del sector público y del régimen autonómico, son entre muchas otras acciones ostensibles del establecimiento del carácter intervencionista del Estado del Bienestar y de la configuración de la estructura social de acumulación del capitalismo regulado.

El carácter regulador-intervencionista del Estado está, en efecto, con base en este objetivo del PLN, particularmente, en las relaciones Estado-economía, asegurando el equilibrio macroeconómico, según el precitado pacto "keynesiano" y las regulaciones establecidas 
por las potencias mundiales en los tratados de Bretton Woods, que se realizaron en 1944. La orientación política quedó establecida en la Carta Fundamental del PLN con lo que se denominó el carácter social de la función económica (objetivo 10) que establece que el incentivo del lucho debía ser complementado $y$ ennoblecido por el espíritu de servicio para dar impulso a una economía de abundancia. El gradualismo como política estatal y acción estratégica para la consolidación del proyecto político del PLN se planteó buscando un equilibrio adaptativo al contexto sociocultural costarricense: "Esta transformación debe efectuarse gradualmente con la elevación de nivel cultural $y$ tomando en cuenta la idiosincrasia nacional".

\section{ANTECEDENTES DEL PROYECTO POLÍTICO EDUCATIVO DEL PARTIDO LIBERACIÓN NACIONAL}

Desde su propio inicio, en el contexto ideológico socialdemócrata, la educación ocupó un lugar preferencial en el corpus discursivo político del PLN. Es preciso recordar al respecto, el carácter esencial que había asumido la educación como parte del nuevo compromiso histórico que había tenido lugar entre capital y trabajo en el marco del pacto keynesiano para el establecimiento del capitalismo regulado:

En el contexto del capitalismo regulado, que se extenderá a lo largo del ciclo de posguerra (el largo boom), tendrán lugar dos pactos socioeducativos: 1) El pacto keynesiano en educación que redefinirá la orientación de la política educativa en los países de capitalismo avanzado, estableciendo un marco de formación de capacidades y competencias para atender las demandas de las escalas de calificación requeridas por la estructura ocupacional del capitalismo regulado; y 2) el pacto socialdemócrata en educación con el que amplía la cobertura y derecho a la educación (como derecho social, esto es, como expresión jurídica del principio político de igualdad) y que fue parte de la estrategia de legitimación del pacto entre trabajo y capital (Miranda, 2007a:14).

Así pues, el PLN se adscribe y asume esos pactos educativos y los integra en su Carta Fundamental, recogiendo las tesis educativas propuestas por el CEPN. En efecto, la Carta Fundamental de 1951 del PLN le confirió una particular importancia a la educación, lo que explica el papel preponderante que esta tendría en el futuro y que se manifestará en las políticas educativas del Estado del Bienestar costarricense. Fue así, como en el corpus doctrinal de su carta fundacional se estipuló, en el artículo 4, el papel central de realizar todo el esfuerzo educacional, con los recursos espirituales y materiales de la sociedad necesarios, en aras de "la formación de un ser humano mejor, capaz de realizar $y$ disfrutar plenamente ese orden económico-social". Esta visión se basó en otra fuente: el artículo 26 sobre la educación, de la Declaración Universal de los Derechos Humanos (DUDH) que como se menciona anteriormente, recogía la visión de la persona humana contenida en su corpus normativo. El artículo 26 de la DUDH estipula:

1. Toda persona tiene derecho a la educación. La educación debe ser gratuita, al menos en lo concerniente a la instrucción elemental y fundamental. La instrucción elemental será obligatoria. La instrucción técnica y profesional habrá de ser generalizada; el acceso a los estudios superiores será igual para todos, en función de los méritos respectivos.

2. La educación tendrá por objeto el pleno desarrollo de la personalidad humana $y$ el fortalecimiento del respeto a los derechos humanos y a las libertades fundamentales; favorecerá la comprensión, la tolerancia y la amistad entre todas las naciones y todos los grupos étnicos o religiosos, y promoverá el desarrollo de las actividades de las Naciones Unidas para el mantenimiento de la paz. 
3. Los padres tendrán derecho preferente a escoger el tipo de educación que habrá de darse a sus hijos.

Como se desprende de esta artículo, el derecho a la educación en las diversas dimensiones contenidas es plenamente coincidente con el principio del bien común, por lo que la educación deviene en un principio central de su proyecto político en la construcción de una base social de apoyo al mismo; pero además, en un factor de movilidad social ascendente en el establecimiento de las condiciones de posibilidad de un amplio sector de "clase media". Estas dos dimensiones se complementan, asimismo, al definir la educación como un factor de integración social en torno a una unidad ideológica para la configuración de la hegemonía política y cultural de orientación socialdemócrata y a la vez, de formación del ejército laboral de reserva calificada necesaria para las escalas laborales que requería el proceso de modernización capitalista en Costa Rica. Proceso que requería, al mismo tiempo, para la reestructuración del capital de acciones, tales como, la diversificación económica agropecuaria, la tecnificación del agro, el desarrollo industrial, la expansión del sector público como ente activo del desarrollo capitalista, la expansión del sector servicios, etc. Estas dimensiones necesarias para la modernización de la estructura económica requería a su vez de: i) una reestructuración del mercado de trabajo, ii) de las escalas de calificaciones y ocupaciones, $y$ por consiguiente, iii) de una respuesta del sistema educativo (función económica, expresada como política educativa) al mercado de trabajo en materia de calificación de la fuerza de trabajo. Estas tareas comprometían seriamente un cambio educativo adquiriendo el rango de objetivos prioritarios de política educativa.

Por otra parte, la canalización de recursos fiscales destinados a la educación, la salud pública y la seguridad social, por parte del Estado del Bienestar no son vistos como "gastos sino inversiones reproductivas espiritual $y$ materialmente". Se trata, en definitiva, de un Estado corporativista e intervencionista, que asume la tarea de concertar las exigencias de la acumulación de capital con el sostenimiento de la paz social y la legitimidad política democrática. En esta dirección el Estado del Bienestar acude al expediente del llamado "salario social" a través de mecanismos redistributivos, basando además, buena parte de su legitimidad democrática en esta forma de intervención, con lo cual se desmercantilizaba algunos espacios de las economías.

\subsection{EL DIAGNÓSTICO CRÍTICO DEL ESTADO DE LA EDUCACIÓN DEL CENTRO DE ESTUDIO DE LOS PROBLEMAS NACIONALES}

El proyecto político educativo del PLN se empezó a construir desde la década de 1940; en efecto, ya desde esa convulsa coyuntura histórica, la educación había sido objeto de análisis crítico. Al respecto, Monge y Rivas observan:

En el referido periodo de 1940 a 1948, la juventud organizada en el Centro de Estudios de Problemas Nacionales (19401945) y después en el Partido Social Demócrata (1945-1949), se dedicó a estudiar la escuela costarricense en todos sus niveles. Estudiantes universitarios, profesionales y profesores, guiados por avanzados principios y doctrinas pedagógicas, analizaron los problemas y fallas que afectaban al sistema y elaboraron programas de gobierno en la materia. Aspiraban a una renovación total de los conceptos de educación, de la relación educandoprofesor, de los métodos de enseñanza. Apoyaban y defendían la reforma sugerida por la Misión Pedagógica Chilena (1978: 126).

Uno de los rasgos que caracterizaba la formación social costarricense, en el periodo inicial de posguerra, era que no contaba con un sistema nacional educativo moderno que respondiera a las nuevas demandas formativas de la niñez y la juventud costarricense. El historiador Carlos Araya Pochet (1968: 31) destaca, asimismo, que el CEPN realizó diagnósticos críticos de los diferentes niveles del sistema educativo, aprovechando 
la alta composición que tenía de "elementos propicios para analizar nuestra problemática educativa", entre ellos educadores, jóvenes profesionales, universitarios y colegiales en la Comisión de educación que coordinaba Carlos Monge Alfaro. Los diagnósticos se realizaron en todos los niveles del sistema educativo. Respecto a la educación primaria se planteaba en sus diagnósticos de 1943, que requería de una reorganización técnica que obedeciera a un análisis riguroso que estuviera basado en "sistemas modernos adaptados consciente $y$ eficazmente a la realidad nacional". En cuanto a la educación secundaria, se apuntaba lo mismo y se añadía la urgente necesidad de contar con personal capacitado. Esta intención política se manifestará en la década de los sesenta con la reforma a la educación secundaria en el gobierno liberacionista de Francisco Orlich (1962-1966). Por otra parte, se denunciaba a la par de la ausencia de "competencia técnica" la asignación de puestos por "compadrazgos y compromisos políticos y familiares", que anulaban los esfuerzos de profesores idóneos que existían en los colegios. En el nivel superior, se abogaba por la autonomía universitaria plena del poder ejecutivo; en el ámbito administrativo, el de selección del personal docente $y$ en la independencia económica (Araya, 1968: 3217).

El estado de la educación costarricense reflejaba el abandono al que estaba sometido por la indiferencia de las élites gobernantes oligárquicas, que no consideraban la necesidad de una reforma estructural de un sistema nacional educativo, que no brindaba eficaces $y$ efectivas posibilidades de movilidad social para la juventud costarricense de mediados del siglo Xx. Por lo tanto, se imponía el ingente reto de una reforma educativa integral del sistema educativo, como parte integrante de una reforma estructural de la formación social costarricense, que pasaba necesariamente por el ineludible paso de arrebatarle el poder exclusivo a la burguesía oligárquica para iniciar

$17 \quad$ Citas tomadas del Centro de Estudio de los Problemas Nacionales. Ideario costarricense: resultado de una encuesta nacional. San José, Imprenta Española: 1943. un nuevo orden sociopolítico y económico, en una sociedad arcaica, polarizada y de una limitada dinámica económica. La realización de una reforma educativa era uno de los aspectos medulares del proyecto político, que sustentaban los sectores sociales emergentes que llevaron adelante la Guerra Civil de 1948, esto se materializó parcialmente en la Constitución Política de 1949. En la Revista Surco se publicaron una considerable cantidad de artículos referidos a la problemática educativa, entre ellos varios escritos por Uladislao Gámez Solano, quien llegó a ser Ministro de Educación Pública de la Junta Fundadora de la Segunda República y posteriormente, en los ulteriores gobiernos de José Figueres Ferrer.

\subsection{EL PACTO CONSTITUCIONAL EDUCATIVO Y LA CONSTITUCIÓN POLÍTICA DE 1949}

En el proceso de configuración del Estado del Bienestar era preciso, como se analizó anteriormente, redefinir su papel creando un nuevo ordenamiento jurídico $y$ las instituciones bases para el inicio del proceso de modernización capitalista (bajo un modelo capitalista regulado con su correspondiente estructura social de acumulación). Esta estrategia de legitimación del proyecto político reformista social tuvo lugar en la misma coyuntura política del denominado "Gobierno de los 18 meses" emprendido por la Junta Fundadora de la Segunda República liderada por José Figueres Ferrer. En efecto, una vez despajado el control del aparato político a la burguesía cafetalera, era preciso un nuevo ordenamiento jurídico, una Constitución Política, cuya estructura se constituyera en un sistema dinámico de normas de grado superior que vertebrase dicho ordenamiento, en su condición de fuerte superior de producción de Derecho. El llamado a integrar una Asamblea Constituyente no se hizo esperar en aras de legitimar la nueva orientación del Estado del Bienestar, como ente promotor de la nueva estructura social de acumulación. Las acciones de la Junta de Gobierno y su interés en la aprobación de una Constitución de corte social demócrata deben comprenderse en la lógica 
política de la configuración de la estructura jurídico-política del Estado del Bienestar costarricense, instrumento indispensable para legitimar las aspiraciones del proyecto político reformista social de los sectores emergentes.

Por consiguiente, la acción de la Asamblea Constituyente en el campo educativo, tuvo como acción central el establecimiento de un referente fundamental que definiera los fundamentos políticos e ideológicos, con que se configuraría el proceso hegemónico educativo ${ }^{18}$, que desde el punto de vista de la socialización político-ideológica, que sirviese en paralelo, de base legitimadora para la implantación del sistema hegemónico reformista social correspondiente al Estado del Bienestar. Este acercamiento analítico nos permite comprender la superación del antiguo régimen liberal en el plano político o ideológico, por un nuevo proyecto político sustentado en nuevas orientaciones ideológicas de corte reformista para la instauración del Estado del Bienestar. La estrategia de legitimación asumida requería ciertamente, de un cambio educativo de orientación reformista social.

El reto que enfrentaban las nuevas clases dirigentes reformistas consistía básicamente, en redefinir el nuevo papel que debía desempenar el sistema educativo ante las nuevas tareas que las clases dirigentes debían enfrentar para la superación del régimen oligárquico-liberal, en los planos político, económico y social. La respuesta del Gobierno de los 18 meses (posteriores al triunfo del Ejército de Liberación Nacional) fue la formulación de una nueva política educativa que expresaba el interés de reformar el sistema educativo, de manera que contribuyera a crear una amplia base social de apoyo al nuevo régimen desde el punto de vista político-ideológico y al mismo tiempo, articulara el eje del proceso de desarrollo económico social; es decir, el proceso de modernización capitalista.

Para el objetivo de establecer la hegemonía social demócrata en la sociedad civil, una de las acciones más importantes de la Junta de Gobierno en su proceso de estatización, fue la

18 Cfr. el ensayo Gramsci y el proceso hegemónico educativo, en Miranda (2006). absorción de la cultura y de la educación como aspectos centrales de sus políticas estatales. Las siguientes palabras del designado como Ministro de Educación de la Junta de Gobierno $y$ la visión del cambio educativo propuesto en la Constitución de 1949:

Gran interés tuvimos para que en la nueva Carta quedaran como preceptos constitucionales, los principios obligatorios para realizar el gran trabajo de una revisión total del quehacer educativo nacional y la fijación de nuevos planteamientos, de nuevas estructuras $y$ de nuevas metas que permitieran adaptar nuestra educación a las necesidades y expresiones del hombre moderno. Los objetivos de don Mauro Fernández se habían cumplido en su totalidad y ahora nos correspondía a nosotros estructurar y realizar nuestros propios planteamientos (Gámez, 1970:27).

Así pues, la educación jugó un papel determinante ante la necesidad de un control por parte del Estado del Bienestar de elevar el nivel técnico cultural de la población, ante las exigencias del desarrollo de las fuerzas productivas y la consolidación de la hegemonía, condición sine que non del proceso de desarrollo capitalista. De esta manera, se readecuaba el papel del sistema educativo en estrecha consonancia con la estructura ideológica de las nuevas clases dirigentes. En referencia a la coyuntura de finales de la década de 1949, en la cual desempeñó un papel protagónico, el Ministro de Educación de la Junta de Gobierno, Uladislao Gámez Solano, designado Miembro de la Junta y Ministro de Educación Pública en el Gobierno de los 18 meses, expresa:

La explosión poblacional, la explosión de aspiraciones; la equivocada y excesiva mecanización del sistema educativo que lo arrastró a una mortal rutina; la peligrosa e inconveniente separación entre las instituciones que instrumentalizan la lucha por romper los marcos del subdesarrollo y las instituciones de educación; los grandes y nuevos enfoques políticos, 
sociales y económicos que caracterizan a la época de la pos-guerra, todo ello me obligó a buscar nuevos horizontes para la Educación Nacional. Esta es la responsabilidad que hemos hecho nuestra los hombres del gobierno, desde 1948 hasta el día de hoy (Gámez, 1973:4).

Antes de entrar a analizar el contenido de los principales preceptos constitucionales en materia educativa, se considera interesante hacer dos anotaciones previas que explican muy bien la orientación que tuvo la educación a partir de ese período.

No obstante, la Asamblea Constituyente había tomado como base la Constitución de 1871, hubo acuerdo en ese órgano colegiado de apartarse de ese texto constitucional en materia educacional. En la toma de esa decisión influyó el hecho que existía consenso en la Asamblea Constituyente, acerca de la necesidad de una reforma profunda del sistema educativo, además se consideraba que el texto de la Carta de 1871 era insuficiente para atender las nuevas demandas en educación en ese momento histórico. Es claro que esa decisión era natural que se tomase, dada la alta composición de intelectuales orgánicos que integraban la Constituyente, vinculados a la educación en todos sus niveles: educadores de prestigio $y$ profesores universitarios. En consecuencia, el texto base de discusión fue el Proyecto de Constitución Política presentado por la Junta de Gobierno (Aguilar, 1973 y Araya, 1968).

En segundo término, la intención original del Proyecto de Constitución de que el Estado tuviese a su cargo la educación como su "función esencial" y la potestad casi exclusiva de crear "las funciones y servicios" para atender las demandas educacionales $y$ culturales del país, fue duramente impugnado por la Iglesia (Aguilar, 1973). Históricamente esto se explica por el conflicto que se genera por la absorción estatizante de la cultura y la educación frente al abandono de estos aspectos del Estado liberal, la consecuencia de esto en el plano político e ideológico se refleja en el caso de la educación, en el "conflicto entre los intelectuales tradicionales (especialmente la
Iglesia), resto del antiguo bloque histórico, y los intelectuales de la clase dominante" (Portelli, 1979:33). Durante el proceso de deliberaciones de la Constituyente, el artículo que contenía la intención mencionada fue finalmente eliminado. Sobre este hecho Aguilar Bulgarelli señala:

La razón de aquella medida fue la siguiente: en torno a este artículo se avecinaban más discusiones, debates, pugnas. Esto se debía a que el asunto ya iba a ser llevado al campo religioso, en vista de que el clero nacional representado por las más altas dignidades eclesiásticas del país, se había manifestado en contra de lo que se dio en llamar 'el monopolio del Estado en la educación' (1973:135).

Este aspecto se constituyó en un acontecimiento importante, desde el punto de vista del proceso de consolidación del sistema nacional educativo pues se asegura el carácter central del sistema educativo como organismo público, quedando establecido el papel predominante del Estado en el campo educativo, como se establecía en el Proyecto de Constitución presentado por la Junta de Gobierno. En efecto, el resultado de esta negociación constituye lo que denominamos el pacto constitucional educativo que configuró el perfil de nuevo sistema nacional costarricense que logró modernizar su estructura y el conjunto de sus funciones sociopolíticas y educativas, para propiciar las ulteriores reformas que tuvieron lugar en las próximas décadas y hasta la actualidad. La tesis es que el pacto constitucional educativo dio lugar al proceso de fortalecimiento de este sistema costarricense, que adquirirá su consolidación con la Ley Fundamental de Educación de 1957, aprobada en el primer gobierno del PLN (primer gobierno constitucional de José Figueres Ferrer, 1953-1957).

Con la Carta Magna de 1949, tuvo lugar uno de los hitos de la historia de la educación costarricense, que se plasmó en el Título VIII, de la EDUCACIÓn Y la CULTURA. Capítulo Único. En el artículo 77 quedó estipulado:

La educación pública será organizada como un proceso integral correlacionado 
en sus diversos ciclos, desde la preescolar hasta la universitaria.

Carlos Monge Alfaro (1973:127) observa que el artículo 77 de la Constitución Política no fue una mera divagación de constituyentespedagogos, sino la culminación de un largo enjuiciamiento que se venía haciendo del sistema educativo costarricense plagado de fallas, como la falta de "coherencia, de unidad, de vertebración al par que dé flexibilidad". El artículo 77, como precepto jurídico, vino a concretar una de las más importantes recomendaciones de la Misión Pedagógica Chilena. Bajo esta disposición constitucional el Estado se asegura el control administrativo del sistema educativo, pero a la vez y lo que es igualmente importante, legitima la potestad del Estado de emprender ajustes. Acerca de este artículo, Uladislao Gámez Solano, Ministro de Educación de la Junta, indicó: "Ajustar la educación a estos conceptos es fundamentar una reforma" (1970:27). La importancia de este artículo radica en este aspecto pues al dejar las posibilidades de modificaciones se establecen las condiciones para una estrecha relación de ajuste entre la dinámica del proceso de desarrollo capitalista, sus cambios estructurales y la respuesta del Estado del Bienestar mediante políticas educativas y curriculares (ya sea como reformas o innovaciones educativas).

Es interesante hacer notar, a propósito de esta cuestión, que desde la óptica del análisis de Gramsci, entre la sociedad civil y la sociedad política (Estado), existe una articulación orgánica de colaboración y complementariedad que se manifiesta en el plano superestructural. Según esta tesis gramsciana dicha vinculación tiene lugar en el ejercicio de la hegemonía. Veamos: según la tesis de Gramsci el papel fundamental es atribuido a la educación por diversas razones: i) la necesidad de que el Estado intervenga en el desarrollo del nivel técnico-cultural para crear las competencias de calificación de la fuerza de trabajo (desarrollo de las fuerzas productivas); ii) la superación del conflicto entre los intelectuales tradicionales (conservadores) y la clase dominante y iii) la necesidad de unificar la ideología difundida por las organizaciones de la sociedad civil. Resulta claro desde esta perspectiva analítica-crítica, que el PLN propugnaba por la construcción de una hegemonía de naturaleza socialdemócrata mediante un proceso de estatización de la sociedad civil ante la decadencia de los partidos tradicionales de la oligarquía, que se manifiesta en la absorción progresiva de la cultura y la educación ${ }^{19}$. Desde esta visión el artículo 77 de la Constitución Política establece el papel intervencionista del Estado en materia educacional, para que el sistema educativo tuviese institucionalmente el poder de adecuar las escalas de calificación de la fuerza laboral a las demandas del desarrollo económico. La intervención estatal, por medio de políticas educativas, propiciará las bases para un avance en la composición técnica de capital necesaria para el desarrollo económico capitalista y al mismo tiempo, deviniera en un medio para legitimar, por medio de un consenso social, el proyecto político socialdemócrata en la sociedad civil.

En el objetivo 4 (capítulo 3) de la Carta Fundamental del PLN, como se ha explicado, el proyecto político socialdemócrata le confiere un papel central a la educación, como eje de la construcción de un ideal de persona humana, como sujeto social y de la sociedad del Bienestar basada en el principio del bien común. Así se estipuló en la Carta Fundamental el papel de la educación en torno al ideal de hombre que se mencionó anteriormente:

Esto exige un esfuerzo educacional dirigido a la formación de un ser humano mejor, capaz de realizar $y$ disfrutar plenamente ese orden económico-social. A esa formación deben concurrir todos los recursos espirituales $y$ materiales de la sociedad.

19 Antes de la fundación del PLN, esto se había puesto de manifiesto en las discusiones sobre la educación que tuvieron lugar en el seno de la Asamblea Constituyente $y$ en el hecho altamente sintomático de que el capítulo correspondiente (Título VII) de la Carta Magna de 1949 se haya titulado: La Educación y la Cultura. 
En este objetivo subyace la idea de que para poder lograr el equilibrio, o más bien, armonizar los intereses de la iniciativa privada (fundados en la libertad individual, que el Estado reconoce y respeta) y el interés colectivo (bien común). Por consiguiente, el Estado deviene en el ente mediador que administra, controla y garantiza este eje hegemónico asegurando la formación de ese "ser humano mejor". Desde su fundación, el PLN asume el pacto socialdemócrata en educación, acorde con la tendencia mundial que tenía lugar en el capitalismo avanzado en la etapa inmediatamente posterior de la Segunda Guerra Mundial, con la clara intención de ampliar la cobertura y el derecho a la educación, como derecho social, en el marco del principio político de igualdad. Esta acción fue parte de la estrategia de legitimación del pacto entre trabajo y capital resultante del balance de fuerza del periodo de posguerra. En estos aspectos básicos se cimentó el pacto constitucional educativo como un primer paso tendente a la legitimación del cambio educativo reformista social, que sería asumido en la Carta Fundamental del PLN, como una expresión programática fundamental de su proyecto político.

Con clara visión del papel de la educación en la puesta en práctica del nuevo proyecto político y económico de corte reformista $y$ desarrollista, las clases emergentes —en particular sus intelectuales orgánicos - supieron orientar el papel de la educación en el marco de la tendencia latinoamericana de cambio de sus fines, enfocados hacia nuevos objetivos de desarrollo económico y social. La educación está concebida, asimismo, desde un criterio "economicista" como inversión reproductiva de acuerdo con las tendencias del modelo de desarrollo económico que preconizaba la CEPAL. Esta nueva racionalidad en el enfoque de la educación, acorde con el cambio en la concepción del desarrollo económico en América Latina, debe interpretarse como la antesala del proceso de redefinición del esquema de dependencia que se iniciaría con mayor profundidad en la década de 1960, el cual se correspondería con una simultánea redefinición del papel y cambio de la estructura del sistema educativo.
Este proceso, como lo apunta Sara Finkel (1979), fue parte de una redefinición de los fines de la educación en Latinoamérica en la década de los cincuenta y los sesenta. Al respecto observa:

Desde las postrimerías de la década del 50, la visión espiritualista de la educación entra en decadencia en América Latina. La discusión acerca de los fines educativos, el sentido del hombre en la historia y demás cuestiones similares, eran temas absolutamente perimidos $y$ sólo servían para detectar la ubicación generacional de los pedagogos. Esta concepción 'metafísica' se reemplaza por una suerte de especulación realista y empresaria de la educación; por lo tanto, los problemas relevantes de estudio son aquellos que se derivan de su producción y eficiencia (1979: 263; la cursiva es propia).

Con base en las consideraciones precedentes, la naturaleza de la política educativa en los años 50, debe interpretarse en Costa Rica teniendo en consideración dos aspectos: por una parte, las nuevas clases dirigentes creaban las condiciones para la adopción del nuevo planeamiento que algunos organismos internacionales estaban promoviendo como una posible salida a la problemática del subdesarrollo —en particular de la Comisión Económica para América Latina (CEPAL) - con el establecimiento del modelo de industrialización por sustitución de importaciones, cuyo puesto en práctica exigía la intervención del poder público como ente planificador del desarrollo; opción enmarcada dentro de la lógica neocapitalista del proceso de acumulación de capital. Por otra parte, el modernizar la educación y el sistema educativo, teniendo como punto de referencia nuevas concepciones psicológicas y educativas más avanzadas en esa época, con la finalidad de adecuar los planes y programas, los aspectos técnicos pedagógicos, etc., conjuntamente con la estructura del sistema educativo, a la lógica del modelo desarrollista. La visión estratégica de este proceso obedecía a la necesidad de capacitar, en distintos niveles 
técnicos, la fuerza de trabajo requerida para el desarrollo industrial que se pretendía impulsar como parte del proceso de modernización de la estructura capitalista del país. Ambos aspectos integrados como propuesta hicieron que tácitamente se produjese el proyecto político reformista, asumiendo como correlato programático el modelo desarrollista.

\subsection{EMERGENCIA DE LA TECNOCRACIA, LA IDEOLOGÍA TECNOCRÁTICA Y EL CAMBIO EDUCATIVO}

En el momento en que se dió el proceso de configuración y consolidación del proyecto reformista social (orientado a consolidar un modelo dependiente de capitalismo regulado), la controversia mundial entre la razón política y la razón técnica, que tuvo lugar a finales de la década de los cincuenta e inicio de los sesenta, se suscitó alrededor del concepto de tecnocracia, un fenómeno ligado al interés por la eficiencia, la competencia profesional en la esfera de la toma de decisiones gerenciales y al progreso técnico ${ }^{20}$. La visión tecnocrática se consolida en el mundo capitalista moderno, a raíz de las condiciones estructurales originadas en la creciente especialización de los avances científicos-tecnológicos, en los procesos de producción industrial y el desarrollo de las industrias como unidades empresariales que conforman el sistema industrial. En este contexto histórico, las tendencias a la concentración de las empresas (en la lógica de consolidación del capital monopolista) y las crecientes y complejas acciones empresariales desencadenan la proliferación de planes generales y programas empresariales, constituyendo un sistema de provisiones, cuya finalidad primordial radica en conferirle racionalidad al desarrollo económico. La instauración de la tecnocracia trajo aparejada la ideología tecnocrática, que asume la racionalidad técnica e instrumental basada en la preeminencia de la eficiencia y la competencia, a su vez, la sobrevaloración de la profesionalización de las decisiones gerenciales al más

20 Se ha desarrollado este aspecto con más amplitud en Miranda (2007). alto nivel; es decir, en el "ápice" de la estructura organizacional de las grandes empresas. El fenómeno tecnocrático trajo aparejado en las sociedades industriales la figura del tecnócrata, el generalista, el manager, que ocupa ese lugar en el nivel más alto del proceso de producción industrial: el director supremo de ese proceso, que utiliza los técnicos o especialistas (los expertos de lo particular), pero que coordina los resultados de la colaboración de los demás y los integra en los mecanismos de decisión empresarial (Fische, 1976).

El papel de la tecnocracia ha sido crucial, desde el punto de la calificación técnica, en el proceso de incorporación dinámica de los diferentes sectores sociales a la esfera de la producción, mediante una especialización teórico-profesional en correspondencia con las demandas generales y coyunturales del desarrollo capitalista. Su principal vinculación ha radicado en la especial atención que le ha conferido a aquellos sectores productivos, que en la dinámica misma de división internacional del trabajo del sistema capitalista, se perfilen como los más innovadores y eficientes para la conducción y organización socio-productiva en función del desarrollo concebido como crecimiento económico. Desde esta orientación, la política educativa asume en los albores del desarrollismo, una decidida orientación hacia la búsqueda de la formación de técnicos para contribuir en el proceso de industrialización dependiente, proceso que en ese momento marcaba el derrotero de desarrollo en razón del buscado "despegue" hacia el capitalismo regulado modernizante. La calificación técnica asume una dimensión económica e ideológica que favorece la hegemonía de la clase dirigente en el marco del orden capitalista. La política educativa inspirada en el desarrollo, orienta un proceso educativo que se pondría al servicio del capital, mediante una formación que permita incrementar la productividad de la fuerza de trabajo como recurso fundamental para la reproducción económica y una formación ideológica tecnocrática - fundada en la falacia de la apoliticidad del tecnócrata- que se postula como política y socialmente neutral. 
Como grupo social los tecnócratas desempeñan un papel estratégico en los procesos de transición o de cambio estructural (como las crisis de acumulación de capital) preconizando la racionalización de concepción técnico-instrumental de la vida social, como ideología. Su accionar se centra en promover y ejecutar las grandes formulaciones estratégicas y los grandes objetivos de las políticas estatales y sus formulaciones programáticas, en el marco de esa visión. Una clara manifestación de la ideología tecnocrática fue, por ejemplo, la irrupción de la visión modernista y los programas desarrollistas que sirvieron de marco de referencia a los planes estatales, en las décadas de los cincuenta y los sesenta (en los cuales la educación ocupó un lugar primordial). Los tecnócratas han desempeñado un papel fundamental en la divulgación y transferencia de la visión tecnocrática empresarial a otras esferas de la gestión pública, entre las cuales está la política educativa. En Costa Rica, este proceso se manifiesta con el advenimiento de la denomina intelligentsia tecno-burocrática de orientación socialdemócrata (Vega, 1982) la cual surge, en paralelo, con el Estado del Bienestar, promoviendo y dinamizando el proceso de consolidación del capitalismo regulado y su estructura social de acumulación.

La tecnoburocracia educativa desempeñó, ciertamente, un papel fundamental en el proceso de cambio educativo, particularmente en la consolidación del sistema nacional educativo costarricense con los aportes y la influencia de los organismos internacionales. Cabe recordar aquí, que en la década de 1950, tuvo lugar la expansión del sistema educativo costarricense por lo que la demanda de asistencia técnica en materia de educación era una prioridad para el país. Esto explica la asistencia de las misiones técnicas de la UNESCO. La primera Misión de Asistencia Técnica de la UNESCO vino en 1951, cuando se desarrollaba en América Latina en ese periodo un programa en la educación fundamental (extensión de la educación primaria a niños y adultos como instrumento de lucha del analfabetismo principalmente en las áreas rurales). La Misión Técnica de la UnEsco propuso proyectos piloto o institucionales como lo señala Dengo (2005:160) - en educación secundaria, vocacional y normal. El inicio de la educación técnica en Costa Rica en 1951, obedeció a una estrategia desarrollista del Estado, como parte fundamental de la modernización capitalista. Es por ello que, la educación vocacional (posteriormente llamada educación técnica) se constituyó en un eje fundamental para la calificación de la fuerza laboral que se sumaría al incipiente proceso industrial, en el marco del modelo de desarrollo sustitutivo de importaciones que promovía la CEPAL. La segunda Misión Técnica de la UNESCo llegó en 1955, que brindó una importante contribución al desarrollo de la educación secundaria, vocacional y académica (Dengo, 2005:163).

\section{LA POLÍTICA EDUCATIVA EN EL PROYECTO POLÍTICO REFORMISTA SOCIAL DEL PLN Y EL MODELO DESARROLLISTA DE LA CEPAL}

El desarrollismo se constituyó en Costa Rica, en una propuesta programática de carácter ideológico-político y económico-social que se integra con el proyecto político social demócrata del PLN: el reformismo-desarrollista. Este modelo se constituye en la modalidad ideológico-política que asumió el Estado en su esquema de dominación y legitimación en la sociedad civil, en las décadas de los cincuenta $y$ posteriormente en los sesenta, del desarrollo político institucional bajo la forma política del Estado del Bienestar costarricense, hasta el inicio de la crisis de legitimación a inicios de la década de los setenta. Esto explica la síntesis discursiva entre la visión reformista social con el modelo de desarrollo de la CEPAL que integró el proyecto político del Partido Liberación Nacional y sus planes de gobierno y que se pusieron de manifiesto especialmente, en las década de 1960. El desarrollismo tuvo como norte el impulso de la modernización capitalista mediante una expansión de las funciones del Estado orientadas a mejorar las condiciones generales de vida de la población, incluyendo a los sectores sociales subprivilegiados y principalmente la clase media (Vega, 1982). 
De esta manera, la política educativa se define esencialmente en función de las orientaciones económico-sociales y del paradigma doctrinalprogramático que integra al desarrollismo con el reformismo. ¿Cuáles son los aspectos que vinculan la política educativa con el modelo desarrollista? Estas son algunas dimensiones que se consideran básicas.

\subsection{EL MODELO DESARROLLISTA, EL PROYECTO} POLÍTICO REFORMISTA SOCIAL Y LA EDUCACIÓN

El desarrollo económico-social, en tanto crecimiento económico, es asumido como la tarea fundamental para superar el subdesarrollo de las sociedades capitalistas modernas e industrializadas, en el marco de la estructura misma. De esta forma, la política educativa deberá promover y garantizar un sistema educativo en el cual los diferentes niveles de la educación se estructuran de tal forma que permitan atender a las necesidades del desarrollo económico-social, tal y como es concebido por el modelo desarrollista. Al respecto, es conveniente subrayar - como lo señala Bonal (1998:22) - la extraordinaria importancia que adquirió la educación formal como mecanismo de asignación, de distribución y de legitimación de las posiciones sociales desde la finalización de la Segunda Guerra Mundial. La concreción de la estrategia de legitimación tuvo como marco el pacto social demócrata en educación como parte de un conjunto más amplio de medidas legitimadoras para establecer la hegemonía de orientación socialdemócrata (Miranda, 2007) ${ }^{21}$ y concretar los cambios reformistas sociales que promovía los sectores sociales emergentes aglutinados en el PLN.

Esta posición fue asumida por la clase dirigente socialdemócrata en Costa Rica y sirvió de base para la racionalización ideológica que articuló la política económica con la política educativa en el proceso de configuración del Estado del Bienestar y la estructura social de acumulación del capitalismo regulado dependiente. La modernización de la estructura capitalista requería, desde un punto de vista

21 Se ha desarrollado una exposición de la estrategia de legitimación en Miranda (2007). económico, de una modernización del sistema educativo para responder desde el Estado a los siguientes procesos: a) el mercado de trabajo para adaptarlo a la reestructuración del capital; b) las escalas de calificaciones y las escalas ocupacionales que tendrán que ajustarse a los nuevos requerimientos del mercado de trabajo; $y$ como consecuencia de todo lo anterior c) la respuesta del sistema educativo (función económica, expresada como política educativa del Estado) al mercado de trabajo en materia de formación-calificación de la fuerza de trabajo (Miranda, 2006:30).

La teoría del desarrollo es, ciertamente, la ideología del crecimiento económico, como factor de progreso, sin alteración de la estabilidad política. El desarrollo es, por consiguiente, una ideología omnipresente que se convierte en un mito, un factor sin el cual no es posible el avance social. Esta ideología es asumida por la clase capitalista en Costa Rica, quienes depositan todas sus esperanzas para modernizar la estructura económica y propiciar el crecimiento económico, que no era otra cosa que el inicio de un proceso de acumulación ampliado de capital. Siendo la educación un factor fundamental para el crecimiento económico, en el contexto del ethos desarrollista predominante en la década de los años sesenta y conscientes de la importancia de la elevación de la cualificación de la mano de obra; las clases dirigentes se plantean la importancia de una reestructuración y readecuación del sistema educativo a los requerimientos del desarrollo económico. En virtud de esa visión, la teoría del capital humano se erige por doble partida, tanto desde el punto de vista teórico, como del programático, en el elemento axial alrededor del cual giraban la concepción desarrollista y el modelo sociopolítico educativo de la modernización pedagógica.

Habiéndose establecido los preceptos constitucionales en materia educativa, el sistema nacional educativo costarricense se preparaba para la modernización de su estructura con claros fines educativos en el contexto del Estado del Bienestar. La orientación socialdemócrata del proyecto educativo del PLN se integró, en una suerte de sincretismo ideológico, 
con la teoría desarrollista que asumía como uno de sus componentes básicos los postulados de la teoría del capital humano. Por lo tanto, los postulados básicos de esta teoría, como se verá más adelante, serán parte, desde el punto de vista económico, de los fundamentos de las reformas que tendrán lugar en las décadas de 1960 y 1970. Por ello, se considera importante exponerlos a continuación. Bonal (1998:41-44) resume los postulados básicos de esta teoría de la siguiente manera:

a) Visión de la educación como cualquier capital físico. La educación se considera como una inversión que produce rentabilidad económica. El ejemplo que utilizó Schultz fue el crecimiento económico de los Estados Unidos en la primera mitad del siglo XX.

b) Relación positiva entre desarrollo económico y las tasas de escolarización en todos los niveles educativos. El efecto de demostración se presenta con las diferencias de la renta nacional y salarial entre los países del norte y los del sur. Esta ventaja comparativa se expresa con la fórmula: inversión educativa = más productividad y por consiguiente, mejor remuneración.

c) Los individuos están en la disposición de conocer el rendimiento que puedan obtener de su inversión en educación. Así, se convierten en capitalistas pues pueden invertir en su propia formación y pueden calcular la tasa media de inversión en educación, tanto en el sector público como en el privado.

d) La educación tiene un efecto redistributivo que favorece el gasto público en ese ámbito. Por tratarse de una inversión financiada casi exclusivamente por el sector público y de un servicio universalista, las rentas más elevadas contribuyen a la financiación de la educación, produciéndose un impacto redistributivo que favorece, al mismo tiempo, el gasto en educación.

e) Requiere de una orientación racional de las pautas del gasto público y privado en enseñanza. Por el carácter público de la inversión, esta requiere de una planificación de la educación que oriente el cálculo de la tasa de rendimiento social de la inversión, de las demandas de mano de obra, como sucedió particularmente en los países subdesarrollados.

\subsection{LA PLANIFICACIÓN ESTATAL Y POLÍTICA EDUCATIVA}

La adopción de la planificación estatal y su vinculación con las políticas estatales es una respuesta del Estado, en caso de que se produzca un decrecimiento de la legitimación (déficit de legitimación) con la consecuente pérdida de lealtad de masas. La ampliación de las materias manejadas administrativamente por el Estado, en su dimensión intervencionista, exige incrementar lealtad de masas para asegurar las nuevas funciones que este asume, como lo plantean Habermas (1999) y Offe (1990) en la teoría de la crisis sistémica desplazada. En este contexto es que se explica la planificación de la formación, ante la asunción por parte del Estado de ámbitos como la administración escolar o el currículo, que pasan a ser partes integrantes de la planificación administrativa general (Habermas, 1999) ${ }^{22}$. Es por esta razón que el proyecto político social demócrata del PLN asumió la planificación en la Carta Fundamental de 1951, como un elemento básico de las acciones estatales con el fin

22 Habermas explica que el surgimiento del sector público es un indicio que el Estado asumió la producción de bienes de uso colectivo aprovechados por la economía privada para disminuir costos. Asimismo, vincula esto al hecho de que la organización estatal del sistema educativo y del progreso científico-técnico incrementa la productividad del trabajo mediante la calificación de la fuerza de trabajo. El progreso científico-técnico implica una enseñanza cada vez más especializada para influir en la productividad. La inversión estatal o privada de fuerza de trabajo altamente calificada (ingenieros, científicos, profesores...) contribuyen a transformar los productos de su trabajo en bienes de uso, disminuyendo los costos e influyendo en la generación de plusvalía. 
de obtener la máxima eficacia de las políticas públicas.

El Estado asume un papel central como ente planificador económico-social que dirige los procesos de cambio estructural para la instauración de la estructura social de acumulación de capitalismo regulado. En este proceso, como ocurrirá en la década de los sesenta, asumirá en paralelo la planificación de la educación para la calificación de los recursos humanos, en aquellas áreas del quehacer productivo requeridas por el desarrollo económico y social. En el ámbito educativo, la planificación educativa se concibe como instrumento fundamental, racionalizador tecno-administrativo y económico-social, para garantizar la eficiencia requerida por el sistema educativo acorde con las exigencias de cambio y reestructuración económica y social, como imperativos del reacomodo de las fuerzas sociales y de la actividad económica-productiva que plantea el desarrollismo como agente programático innovador. En consecuencia, la planificación deviene en una acción técnicopolítica que el Estado asume para racionalizar la función del sistema educativo, promoviendo la calificación de los técnicos y profesionales que demanda la división técnica del trabajo en el proceso de modernización capitalista. Asimismo, coadyuva en la estructuración social estableciendo los fundamentos del consenso social y la lealtad de masas para legitimar su proyecto político. Desde esta perspectiva, el proyecto político reformista del PLN concibió la política educativa como un factor legitimador de su propuesta de cambio estructural, orientando y consolidando los intereses hegemónicos de la clase dirigente reformista.

\section{REFLEXIÓN FINAL}

El proyecto educativo del PLN, en síntesis, asumió las siguientes orientaciones programáticas:

a) Es impulsado en un primer momento por sectores sociales emergentes, fundamentalmente de extracción pequeño burguesa y de clase media $y$ tiende a consolidarse sobre la base de un cambio cualitativo de estos sectores, que una vez en el poder, llegan a asumir un carácter compatible con la modalidad de comportamiento propia de la clase dirigente.

b) En consonancia con la teoría del capital humano establece ciertas orientaciones básicas de la política educativa en cuanto a las pautas del gasto público, por niveles y modalidades educativas, en función de criterios de eficiencia económica e inversión capaz de generar rentabilidad económica. Así, la teoría del capital humano sirvió de formulación teórica en la visión desarrollista de los años cincuenta que justificaba la función tecnológica y económica de la educación $y$ el uso eficiente de los recursos humanos, de acuerdo con la tendencia mundial al respecto.

c) Contribuye de acuerdo con el carácter mesoclasista del proyecto político del PLN y modifica las pautas de movilidad social de la población en un proceso de ampliación de las capas medias (para cerrar la brecha social), en una coyuntura de un acelerado proceso de crecimiento en la población, que incide directamente en una expansión del sistema educativo y de la concepción funcionalista de la educación que preconiza la igualdad de oportunidades educativas. Esto explica la estructuración modernizante del sistema educativo y el papel estratégico de la reforma en la enseñanza media a principios de los sesenta $y$ posteriormente, en el gobierno de Figueres Ferrer (1970-1974); reforma integral que se promovió con el Plan Nacional de Desarrollo Educativo.

d) Se expresa y materializa en medidas y reformas educativas que en el marco del reformismo social y económico, en general, deben ser concebidas como factores de integración social capitalista que se impulsa por medio del cambio 
educacional (ampliación de la cobertura del sistema educativo, depuración técnico-administrativa, función redistributiva de la educación, igualdad de oportunidades, modernización pedagógico-programática y curricular, capacitación de recursos, etc. Acciones que corresponden con las exigencias de la sociedad, permitiendo introducir modificaciones $y$ aportar alternativas y recursos para el desarrollo social sin trascender el sistema social vigente; es decir, sin una ruptura cualitativa con la estructura de la sociedad capitalista; en otras palabras, se tratará de introducir cambios en el sistema para mantenerlo $y$ perpetuarlo.

e) Promueve el concepto de la "democratización" entendida como la búsqueda de una participación de todas las fuerzas sociales en su condición de gestoras del sistema educativo y beneficiadas directas del mismo. Esta acción representa una estrategia hegemónica de la clase dirigente destinada a garantizar, en -y a través - de la sociedad civil, el consenso social necesario para obtener la hegemonía política y cultural requerida para la legitimación de su proyecto político y por consiguiente, para la implantación de la estructura social del capitalismo regulado.

Desde este posicionamiento programático la política educativa, en el marco del proyecto político reformista-desarrollista, contribuirá a crear $y$ facilitar las condiciones objetivas para que se produzca, en el marco del capitalismo regulado dependiente, la modernización de la estructura capitalista de la formación social costarricense. La reforma al sistema nacional educativo costarricense, como parte de la estrategia interventora del Estado del Bienestar, contribuirá, por consiguiente, i) al proceso de acumulación de capital aportando fuerza de trabajo calificadas a distintas escalas y ii) a la conformación y consolidación de un sistema hegemónico de orientación ideológica social reformista.
En el periodo de referencia, bajo el modelo regulado del Estado del Bienestar y en el marco del proyecto político reformista, la política educativa asume el núcleo ideológico del desarrollismo, para asumir la tarea fundamental de crear y facilitar las condiciones objetivas, para que se reproduzca de la manera más dinámica y productiva el sistema capitalista. Este proceso tuvo como norte responder a las demandas del proceso de modernización capitalista y mantener la hegemonía política-cultural para lo cual utilizó como elemento mediático el modelo de reforma educativa de la modernización pedagógica y el modelo del reformismo social — siguiendo la tipología de Latapí (1980). En respuesta a las demandas sociopolíticas y en aras de la configuración del Estado del Bienestar y del proceso de modernización de capitalismo regulado, el trasfondo sociopolítico del proyecto educativo del PLN en su etapa fundacional obedeció a tres estrategias de legitimación cardinales:

1. Impulsar la creación y desarrollo de un proceso educativo cuyas estructuras sirvan adecuadamente, de acuerdo con el grado de desarrollo alcanzado por el sistema capitalista en las formaciones económico-sociales dependientes, a los intereses expansionistas de este. Con ello, se pretende también, hacer más eficiente y dinámica la estructura productiva, a fin de conservar $y$ modernizar la estructura capitalista en general, bajo la modalidad de capitalismo regulado.

2. Legitimar la orientación reformista so-cial del Estado del Bienestar y el necesario consenso para mantener la lealtad de masas requerido para el equilibrio sociopolítico ( $y$ así evitar la crisis del sistema). Crear las condiciones para que se especialicen los sistemas de producción y difusión ideológica desde el sistema educativo, para incorporar selectiva y marginalmente, en algunos casos, a los diferentes sectores sociales y poblacionales al proceso de modernización de la estructura 
capitalista, ampliando, de esta forma, las redes de hegemonía ideológica como medio para universalizar los intereses particulares de la clase dirigente.

3. Fijar las orientaciones metodológicas y doctrinales para que el sistema educativo logre recrear y promover una ideología consecuente con la modernización capitalista, para lo cual se promueve fundamentalmente la ideología de la "modernidad", en el área de la ciencia y la tecnología (ideología tecnocrática), etc.

Con la fundación del PLN en 1951, se establecieron los fundamentos sociopolíticos del proyecto político educativo reformista social que orientarían ulteriormente, la política educativa de sus posteriores gobiernos en aras de realizar el cambio educativo de la segunda mitad del siglo xx en Costa Rica. Este proceso se coronaría con la promulgación de la Ley Fundamental de Educación de 1957, marco jurídico que completaría el establecimiento de la plataforma jurídica, sociopolítica y educacional que orientarían los futuros cambios educativos de inclinación reformista social, en un contexto de implementación del modelo desarrollista en la década de los sesenta. Asimismo, la reforma educativa, formulada en el Plan Nacional de Desarrollo Educativo que tuvo lugar en el gobierno de Figueres (19701974), promovido por el Ministro de Educación, Uladislado Gámez Solano ${ }^{23}$, fue en gran medida la materialización del cambio educativo impulsado en el marco del proyecto político social demócrata del PLN.

$23 \quad$ Miembro del Centro de Estudio de los Problemas Nacionales, miembro de la Junta de Gobierno de la Segunda República, uno de los fundadores del PLN y uno de los intelectuales orgánicos más destacados del proceso de cambio educativo de orientación reformista social.

\section{BIBLIOGRAFÍA}

Aguilar Bulgarelli, Óscar. La Constitución de 1949. Antecedentes y proyecciones. San José: Editorial Costa Rica, 1973.

Aguilar Bulgarelli, Óscar. Costa Rica y sus hechos politicos de 1948. Problemática de una década. San José: Editorial Costa Rica, 1983.

Araya Pochet, Carlos. Historia de los partidos politicos. Liberación Nacional. San José: Editorial Costa Rica, 1969.

Bonal, Xavier. Sociología de la Educación. Una aproximación crítica a las corrientes contemporáneas. Barcelona: Paidós, 1998.

Carro Zúñiga, Alfonso. "Prólogo". El Pensamiento Social Demócrata. San José: Editorial Costa Rica, 1986.

Castells, Manuel. "El futuro del Estado del Bienestar en la sociedad informacional". Revista SISTEMA 131. 1996:35-53.

Centro de Estudio de los Problemas Nacionales. Ideario costarricense: resultado de una encuesta nacional. San José: Imprenta Española, 1943.

Delgado, Jaime. El Partido Liberación Nacional. Análisis de su discurso político-ideológico. Heredia: EUNA, 1980.

Dengo, Ma. Eugenia. Educación costarricense. San José: Editorial EunED, 2005.

Figueres Ferrer, José. "La orientación general de la Segunda República". [Discurso de apertura de la Asamblea Constituyente], 16 de enero de 1949. En: Carro, Alfonso (comp.). El pensamiento socialdemócrata. Biblioteca Patria. San José: Editorial Costa Rica, 1986.

Finkel, Sara. "El capital humano; concepto ideológico". En: Labarca, Guillermo et ál. La Educación Burguesa. México DF: Editorial Nueva Imagen, 1979.

Fische, Lorenzo. "Tecnocracia". En: Bobbio, Norberto y Matteucci, Nicola. Diccionario de política. Madrid: Tecnos, 1987. 
Habermas, Jürgen. Problemas de legitimación en el capitalismo tardio. Madrid: Ediciones Cátedra, 1999.

Jonas Bondenheimer, Susanne. La ideología social demócrata en Costa Rica. San José: Editorial Universitaria Centroamericana EDUCA, 1984.

Latapí, Pablo. Análisis de un sexenio de educación en México, 1970-1976. México: Editorial Nueva Imagen, 1980.

Miranda, Guillermo. "Gramsci y el proceso hegemónico educativo". Revista Educare IX. CIDE, Costa Rica: Editorial de la Universidad Nacional EUNA, 2006.

Miranda, Guillermo. "Política curricular, crisis de legitimación y hegemonía neoliberal". Revista de Ciencias Sociales. Edición temática: El debilitamiento de la democracia en el capitalismo desregulado 112-113. Universidad de Costa Rica, 2007a.

Miranda, Guillermo. "Reforma e innovación educativa. Consideraciones teóricas para la investigación crítica”. Revista Educare IX (2). CIDE. Costa Rica: Universidad Nacional EUNA, 2007b.

Monge Alfaro, Carlos y Rivas Ríos, Francisco. La educación: fragua de una democracia. San José: Editorial de la Universidad de Costa Rica, 1984.

Montenegro, Walter. Introducción a las doctrinas político-económicas. México: Fondo de Cultura, 1986.

Offe, Claus. Contradicciones en el Estado del Bienestar. Madrid: Alianza, 1990.

Partido Liberación Nacional. Carta Fundamental del Partido Liberación Nacional de 1951. En: <www.pln.or.cr/docs/1cfpln. doc $>$
Portelli, Hugues. Gramsci y el bloque histórico. México: Siglo XXI Editores, 1979.

Riutort Serra, Bernart. Razón politica, globalización y modernidad compleja. España: El viejo topo, 2001.

Rojas, Manuel. Lucha social y guerra civil en Costa Rica: 1940-1948. San José: Editorial Porvenir, 1979.

Rovira Mas, Jorge. Estado y política económica en Costa Rica. 1948-1970. San José: Editorial Porvenir, 1983.

Salazar Mora, Jorge Mario. Calderón Guardia una biografía política. San José: UNEDMinisterio de Cultura, Juventud y Deportes, 1985.

Solís, Manuel y Esquivel, Francisco. Las perspectivas del reformismo en Costa Rica. San José: Departamento Ecuménico de Investigaciones DEI y Editorial Universitaria Centroamericana EDUCA, 1980.

Sping-Andersen, Gosta; Friedland, Roger y Olin Wrigth, Erik. "Los modos de lucha de clases y el Estado capitalista". En: Claus Offe y otros. Capitalismo y Estado. Madrid: Editorial Revolución, 1985.

Vega Carballo, José L. Poder político y democracia en Costa Rica. San José: Editorial Porvenir, 1982.

Vega Carballo, José L. Hacia una interpretación del desarrollo costarricense. San José: Editorial Porvenir, 1983.
Fecha de ingreso: 15/11/2010 Fecha de aprobación: 19/11/2010 
